\title{
A Kinetic Energy Budget and Internal Instabilities in the Fine Resolution Antarctic Model
}

\author{
V. O. IVCHENKO \\ Department of Oceanography, University of Southampton, Southampton, United Kingdom \\ A. M. TReguier \\ Laboratoire de Physique des Oceans, IFREMER, Brest, France \\ S. E. BEST \\ Department of Oceanography, University of Southampton, Southampton, United Kingdom
}

(Manuscript received 18 May 1995, in final form 8 April 1996)

\begin{abstract}
An energy analysis of the Fine Resolution Antarctic Model (FRAM) reveals the instability processes in the model. The main source of time-mean kinetic energy is the wind stress and the main sink is transfer to mean potential energy. The wind forcing thus helps maintain the density structure. Transient motions result from internal instabilities of the flow rather than seasonal variations of the forcing.

Baroclinic instability is found to be an important mechanism in FRAM. The highest values of available potential energy are found in the western boundary regions as well as in the Antarctic Circumpolar Current (ACC) region. All subregions with predominantly zonal flow are found to be baroclinically unstable. The observed deficit of eddy kinetic energy in FRAM occurs as a result of the high lateral friction, which decreases the growth rates of the most unstable waves. This high friction is required for the numerical stability of the model and can only be made smaller by using a finer horizontal resolution. A grid spacing of at least $10-15 \mathrm{~km}$ would be required to resolve the most unstable waves in the southern part of the domain.

Barotropic instability is also found to be important for the total domain balance. The inverse transfer (that is, transfer from eddy to mean kinetic energy) does not occur anywhere, except in very localized tight jets in the ACC.

The open boundary condition at the northern edge of the model domain does not represent a significant source or sink of eddy variability. However, a large exchange between internal and external mode energies is found to occur. It is still unclear how these boundary conditions affect the dynamics of adjacent regions.
\end{abstract}

\section{Introduction}

The Southern Ocean is an important part of the World Ocean. Both deep and intermediate water masses are formed in this region, which is characterized by intense ocean-atmosphere exchanges of momentum and heat and a large poleward heat flux. Transient eddies resulting from baroclinic instability are thought to play a large part in the momentum and heat balance of the Southern Ocean. This view comes mainly from theory and idealized quasigeostrophic models.

Evidence for the importance of transient eddies in the dynamics of the Southern Ocean is sparse because it is

Corresponding author address: Dr. Vladimir O. Ivchenko, Department of Oceanography, University of Southampton, Southampton SO17 1BJ, United Kingdom.

E-mail: voi@soton.ac.uk a remote region that often has bad weather and sea ice. The surface eddy kinetic energy, estimated from FGGE drifters (Patterson 1985) and satellite altimetry (Chelton et al. 1990), is greater than the time-mean kinetic energy. Furthermore, direct measurements have shown that the eddy heat flux is large in the Drake Passage region of the ACC (Bryden 1979). Indirect evidence for the global importance of the eddy heat flux in the Southern Ocean has been provided by De Szoeke and Levine (1981). They have calculated the heat flux due to the timeaveraged geostrophic velocity and show that it cannot account for the oceanic heat loss in the Southern Ocean.

The U.K. FRAM (Fine Resolution Antarctic Model) experiment was the first attempt to represent the dynamics of the Southern Ocean with a high-resolution primitive equation model, allowing eddy activity to develop. FRAM results are described by The FRAM Group (1991) and Webb et al. (1991). Many specific analyses of the experiment have been performed. How- 
ever, no quantitative picture of the relative importance of transient eddies and baroclinic instability processes in FRAM has emerged so far. Thompson (1993) shows that the heat flux across the $1.3^{\circ}$ contour results primarily from transient eddies, as suggested by De Szoeke and Levine. On the other hand, analyses by Stevens and Ivchenko (1996, hereafter SI) and Ivchenko et al. (1996) point out the importance of stationary eddies and lateral friction in the momentum balance. Finally, Stevens and Killworth (1992) emphasize the low level of eddy kinetic energy near the surface in FRAM.

It is important to have a clear view of the instability processes in FRAM in order to assess to what extent FRAM is an eddy-resolving model and whether a further increase in resolution is needed before the Southern Ocean can be modeled realistically. Since the Southern Ocean is a very inhomogeneous ocean, such an assessment can be made only on a regional basis. We believe that a thorough analysis of the kinetic energy balance as in Treguier (1992) or Beckmann et al. (1994) is the best tool to reveal the instability processes in the model.

The energy analysis presented here complements the study of the momentum balance performed by SI, Ivchenko et al. (1996), and Killworth and Nanneh (1994). The FRAM energy balance is also compared with the energy balances of other models to contrast channel dynamics with those of a closed basin.

\section{FRAM model}

FRAM is a British numerical model with a high resolution $\left(0.25^{\circ}\right.$ in latitude, $0.5^{\circ}$ in longitude, and 32 depth levels). This corresponds to a grid size close to $27 \mathrm{~km}$ in the horizontal and varying from 20 to $230 \mathrm{~m}$ in the vertical. The numerical code is based on the GFDL model developed by Cox (1984). The numerical method of solution conserves energy, momentum, and tracer content and variance.

The model domain stretches from $24^{\circ} \mathrm{S}$ to the Antarctic continent. At the northern boundary, the open boundary condition combines a Sverdrup balance for the barotropic component and a linear radiation condition for the baroclinic component (Stevens 1990).

FRAM has been initialized by relaxing the temperature and salinity fields to the climatological hydrography of Levitus (1982). This data assimilation has been removed after 6 years of the model run, except at the surface where there is a relaxation to the Levitus annual average of temperature and salinity. The relaxation time is 1 year. The wind stress forcing is from Hellerman and Rosenstein (1983). The model has been run for a total of 16 years and the analysis in this experiment uses data from the last 6 years. The energy is almost statistically steady during this period (Stevens and Killworth 1992), although the deep temperature and salinity fields are not in equilibrium (Killworth and Nanneh 1994).

The horizontal viscosity is both harmonic $\left(\nabla^{2}\right)$ and biharmonic $\left(\nabla^{4}\right)$ with coefficients of $10^{2} \mathrm{~m}^{2} \mathrm{~s}^{-1}$ and $-5 \times 10^{10} \mathrm{~m}^{4} \mathrm{~s}^{-1}$, respectively, while the horizontal diffusivity is harmonic with a coefficient of $200 \mathrm{~m}^{2} \mathrm{~s}^{-1}$. The vertical diffusion coefficients are $10^{-4} \mathrm{~m}^{2} \mathrm{~s}^{-1}$ for momentum and $0.5 \times 10^{-4} \mathrm{~m}^{2} \mathrm{~s}^{-1}$ for temperature and salinity. There is a momentum flux due to quadratic bottom friction, with drag coefficient $C_{d}=0.0014$.

The basic dynamics of the FRAM model are revealed by the momentum balance (SI; Ivchenko et al. 1996). In the zonal momentum equation, both depth and zonally averaged along a latitude circle passing through Drake passage, the main balance is between the wind stress and the topographic form stress. This is in agreement with multilayer quasigeostrophic models (McWilliams et al. 1978; Treguier and McWilliams 1990; Wolff et al. 1991). In these models the zonal momentum is transmitted downward by the interfacial form stress, which does not explicitly appear in a continuously stratified primitive equation model. Stevens and Ivchenko (SI) estimate this term using the quasigeostrophic theory of Johnson and Bryden (1989) and prove that it can balance the wind stress. This result is confirmed by the isopycnal analysis of Killworth and Nanneh (1994). The zonally averaged interfacial form stress is mainly due to stationary eddies, again in agreement with quasigeostrophic models. The horizontal Reynolds stress divergence in FRAM is found to be smaller than in quasigeostrophic models, however.

Marshall et al. (1993) and Ivchenko et al. (1996) point out that a momentum budget along latitude lines can be misleading because the core of the current undergoes large meridional excursions (Fig. 1). Ivchenko et al. (1996) have calculated the momentum balance along isolines of the time-averaged barotropic streamfunction in order to follow the path of the ACC more closely. Although the depth-averaged balance is still mainly between wind stress and topographic stress, the lateral friction is no longer negligible (between $15 \%$ and $50 \%$ of the form stress and even higher on the southern flank of the circumpolar current). Bottom friction and vertical diffusion of momentum also play a part. In quasigeostrophic models transient eddies, resulting from the baroclinic instability of the mean flow, are responsible for the vertical penetration of momentum down from the wind-forced surface layers to the ocean floor. Ivchenko et al. (1996) show that this picture is more complicated in FRAM because of the meridional thermohaline circulation and that isopycnals outcrop. This demonstrates that in FRAM the wind-driven and thermohaline dynamics are intimately linked.

\section{Spatial inhomogeneity of the kinetic energy}

The kinetic energy distribution in FRAM has been compared with FGGE drifters and moorings by Stevens and Killworth (1992). We include here pictures of the mean and eddy kinetic energy (Figs. 2 to 4 ) similar to 


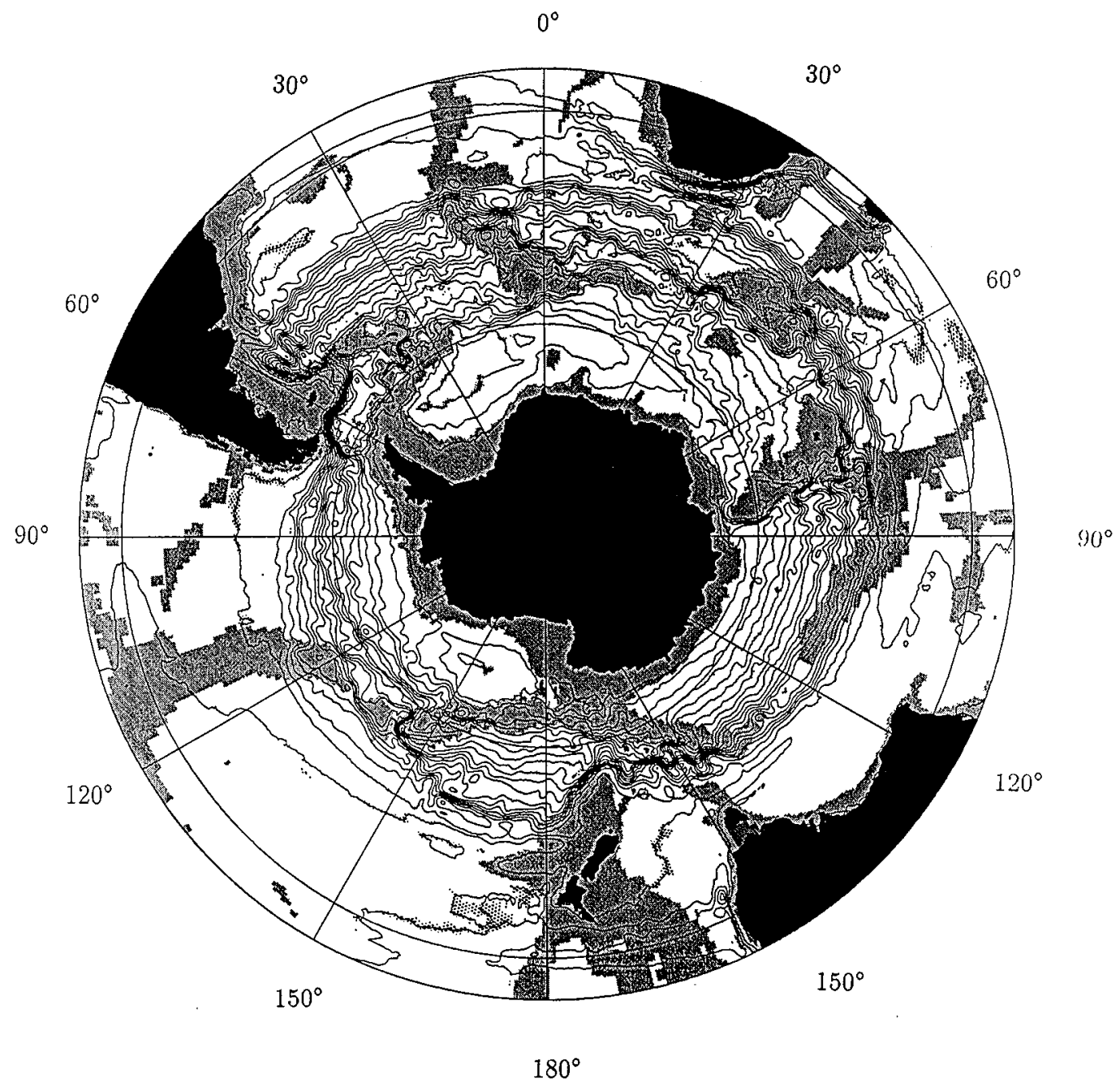

FIG. 1. The time-mean mass transport streamfunction. The contour interval is 10 Sverdrups. Major topographic features (with a depth of less than $3000 \mathrm{~m}$ ) are represented by shading (after SI).

theirs because the spatial inhomogeneity that they reveal is the basis for our regional analysis.

In the Southern Ocean the most energetic regions are in the Antarctic Circumpolar Current (ACC) and near western boundaries. This distribution is well reproduced in FRAM. Maxima of energy occur in the vicinity of Drake Passage, the Agulhas Current, and near both Crozet and Kerguelen Plateaus (Fig. 2). However, the level of kinetic energy in FRAM is much smaller than that observed by FGGE drifting buoys. Patterson (1985) finds values over $500 \mathrm{~cm}^{2} \mathrm{~s}^{-2}$ over huge areas to the north of $60^{\circ} \mathrm{S}$. In FRAM, such values occur only at the western boundaries, in the Agulhas region and near strong topographic features. The FGGE drifting buoys tend to accumulate at fronts (Hoffman 1985) and, therefore, may overestimate the kinetic energy. However, this effect alone cannot explain the deficit of kinetic energy in FRAM (Stevens and Killworth 1992).

Such a deficit does not occur for the time-mean ki- netic energy. In fact, the mean kinetic energy in FRAM is even higher than that measured by FGGE buoys in the western Atlantic. The reason for this is probably that the 5 degree averaging used by Patterson (1985) does not resolve the energetic narrow flows represented in FRAM (for example, after Drake Passage, Fig. 2).

On the other hand, the kinetic energy of transient eddies (EKE) is too low everywhere in FRAM. It is at best $25 \%$ of the observed level according to Stevens and Killworth (1992). This is confirmed by a comparison with TOPEX altimeter data provided by Y. Le Traon (1995, personal communication; the data processing is described in Le Traon et al. 1994). Figure 3b shows the variance of geostrophic velocity calculated along the satellite tracks assuming isotropy. In the Agulhas, west of Australia, and in the Malvinas-Brazil confluence zone FRAM EKE is not much greater than 1000 $\mathrm{cm}^{2} \mathrm{~s}^{-2}$ (Fig. 3a), while TOPEX values reach $3181 \mathrm{~cm}^{2}$ $\mathrm{s}^{-2}$. Eddy kinetic energies greater than $300 \mathrm{~cm}^{2} \mathrm{~s}^{-2}$ and 


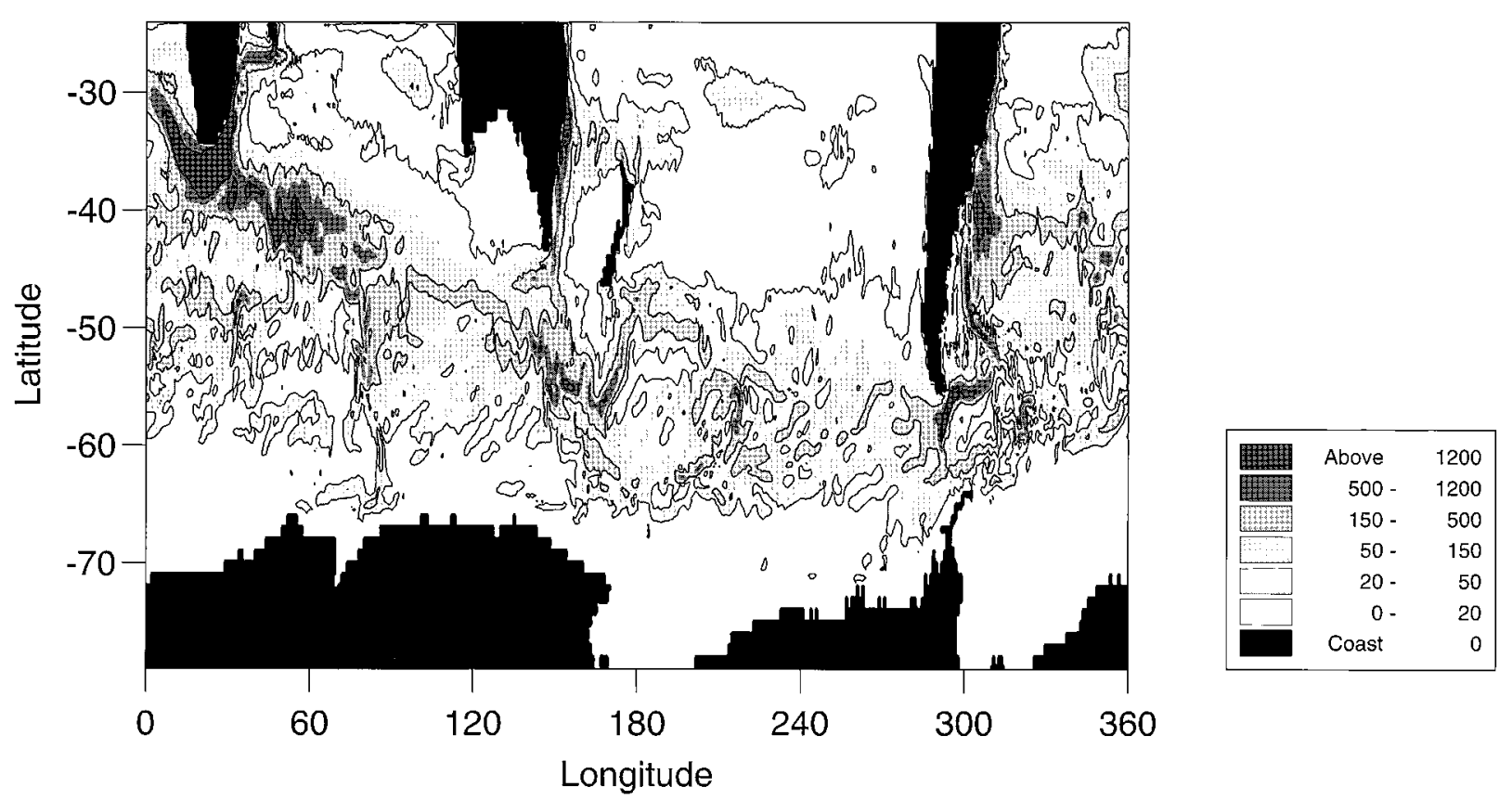

FIG. 2. Total kinetic energy in the top model layer $(20.7 \mathrm{~m})$, calculated over the last 6 years of the FRAM run. Contours are in units of $\mathrm{cm}^{2} \mathrm{~s}^{-2}$.

reaching $700 \mathrm{~cm}^{2} \mathrm{~s}^{-2}$ are found over the most part of the ACC in the TOPEX data, while in FRAM, EKE barely exceeds $100 \mathrm{~cm}^{2} \mathrm{~s}^{-2}$ in these regions. For both TOPEX and FRAM, high eddy kinetic energies are found in regions of high mean flow and/or near topographic features, supporting the hypothesis that eddies arise by barotropic and baroclinic internal instability of the flow. The highest values of EKE occur in the Agulhas region, near the southeast coasts of Australia and South America, and near the strong topographies of Crozet Plateau and southeast of New Zealand. This led Stevens and Killworth to suggest that eddy generating processes are present in FRAM but are not active enough. The energy analysis presented here will help us quantify this problem.

Both Stevens and Killworth (1992) and Ivchenko et al. (1996) have analyzed the vertical structure of kinetic energy. Stevens and Killworth emphasize that the strongest penetration of kinetic energy occurs in the ACC. In regions north and south of the ACC the kinetic energy is more surface intensified. Note that eddy kinetic energy decreases more rapidly than the time-mean in the upper layers (above $1000 \mathrm{~m}$ ) but more slowly than the time mean down to the bottom. This may be attributed to bottom-intensified variability (topographic Rossby waves). Large values of EKE appear east of the main topographic obstacles (for example at a depth of $3071 \mathrm{~m}$, in Fig. 4).

Because the Southern Ocean is very inhomogeneous, as revealed by Figs. 2 to 4, the energy analysis of the total domain may be misleading. We have therefore split the model domain into regions. The criteria for this arbitrary partition are that each subdomain should be (more or less) homogeneous and that the number of subdomains should be as small as possible. Two analyses have been performed:

Experiment 1: There are four subdomains (Fig. 5). The rationale is to single out a zonal channel at the Drake Passage latitudes (ACC belt, or ACCB). This region has no meridional barriers at all, and it is the region to which idealized channel models are supposed to apply. Ivchenko et al. (1996) have noted that a large part of the ACC flows north of this ACC belt region. Consequently we identify a further subdomain, the North ACC (NACC). The other regions are the southern part of the domain (Antarctic Zone or Anzone) and the northern part (subtropical region).

Experiment 2: A single region with a complicated geometry (Fig. 6) is defined covering the whole ACC path. Western boundary regions have also been singled out near Africa (Agulhas region), Australia (WestPac region), and South America (WestAtl). The other regions are: Indian, Pacific, Atlantic, and again an Antarctic zone to the south of the ACC.

The total kinetic energy for the whole domain is partitioned into $58 \%$ for the mean and $42 \%$ for the eddy component of the flow. Energies for individual regions appear in Figs. 5 and 6. In experiment 2, the ACC region contains most of the kinetic energy; that is, $72 \%$ of the total domain mean and $51 \%$ of total domain eddy kinetic energy. A similar result is found in the ACC regions of experiment 1 . Most of the eddy kinetic energy, $79 \%$, is 


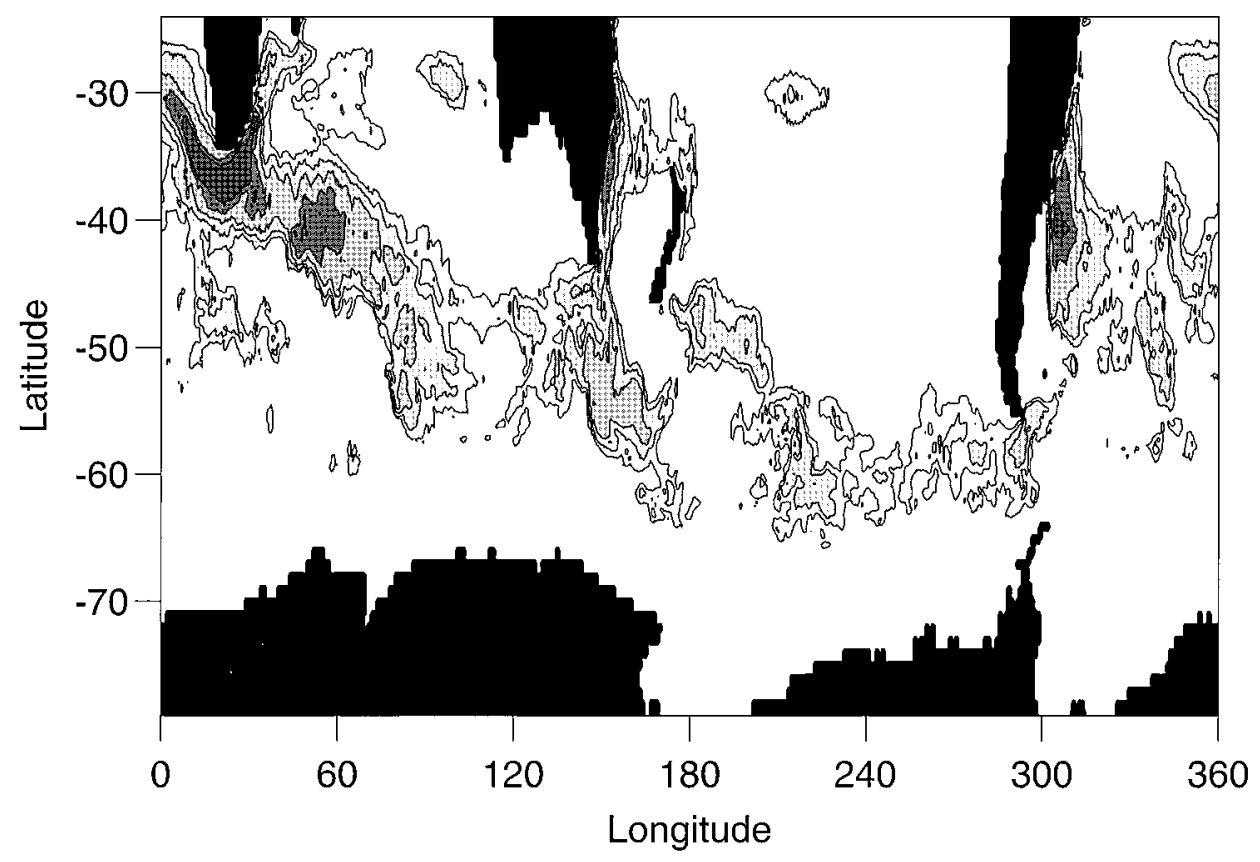

\begin{tabular}{|c|c|c|}
\hline & Above & 1200 \\
\hline 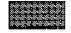 & $500-$ & 1200 \\
\hline WWE & $150-$ & 500 \\
\hline & $50-$ & 150 \\
\hline & $20-$ & 50 \\
\hline & $0-$ & 20 \\
\hline & Coast & 0 \\
\hline
\end{tabular}

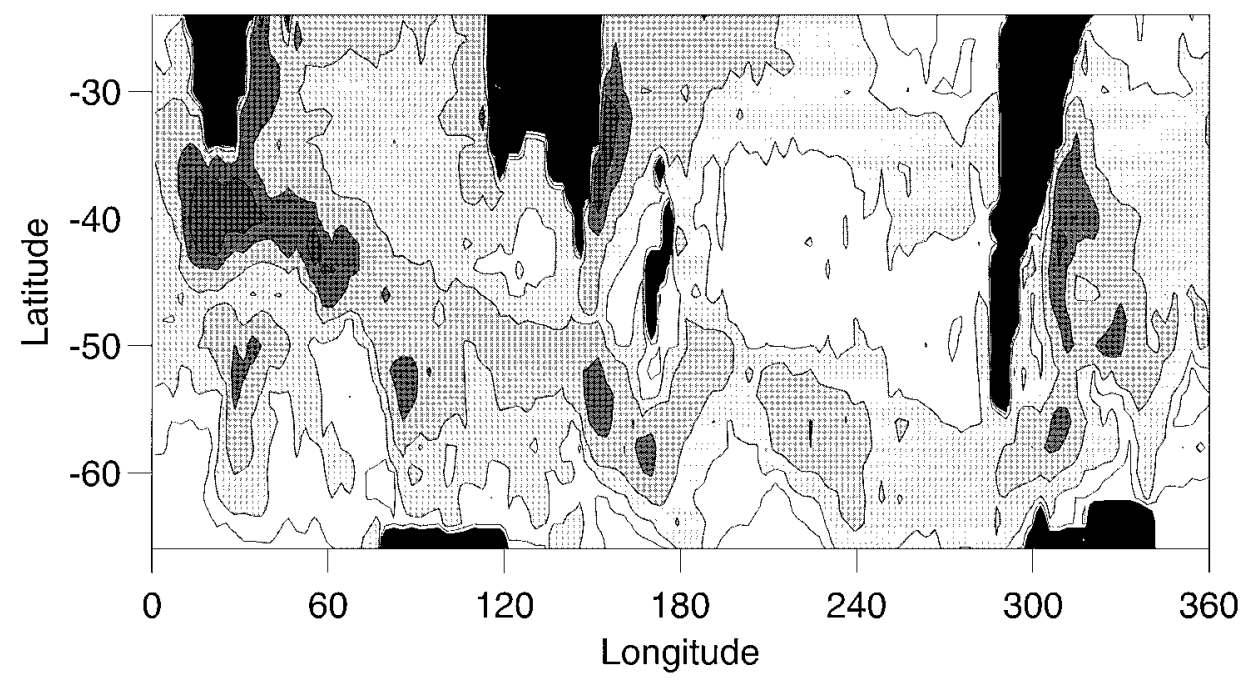

\begin{tabular}{|c|c|c|}
\hline 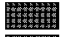 & Above & 1200 \\
\hline & $500-$ & 1200 \\
\hline E. & $150-$ & 500 \\
\hline & $50-$ & 150 \\
\hline & $20-$ & 50 \\
\hline & $0-$ & 20 \\
\hline & Coast & \\
\hline
\end{tabular}

FIG. 3. (a) Eddy kinetic energy in the top model layer, calculated over the last 6 years of the FRAM run. (b) Variance of the geostrophic velocity from TOPEX data (courtesy of P.Y. Le Traon). Contours are in units of $\mathrm{cm}^{2} \mathrm{~s}^{-2}$.

generated in the NACC, with only $21 \%$ in the ACCB. Another very important contribution of EKE comes from the Agulhas region, which generates more than $26 \%$ of the EKE of the Southern Ocean within only $3.4 \%$ of the total model volume.

The ratio of eddy to mean kinetic energy clearly decreases poleward. Such a decrease has been found in other eddy-resolving, primitive equation models (for example, Böning and Budich 1992). They suggest that this decrease is due to the fact that the unstable scales are smaller in the polar regions because the Rossby radius is smaller, rendering the model resolution inadequate there. That this also happens in FRAM is demonstrated in section $5 \mathrm{c}$.

The partition between internal mode and external mode kinetic energy has also been calculated for the different regions. In the total domain the barotropic mode contains $61 \%$ of the total energy. Of the subregions (excluding the Anzone) the ACC region is the most barotropic with $69 \%$ of its energy in the external mode. The Agulhas region is the most important region where the internal mode has more kinetic energy $(55 \%)$ than the external mode. Other, less energetic regions where this occurs are the Atlantic, Indian, and WestPac regions. 


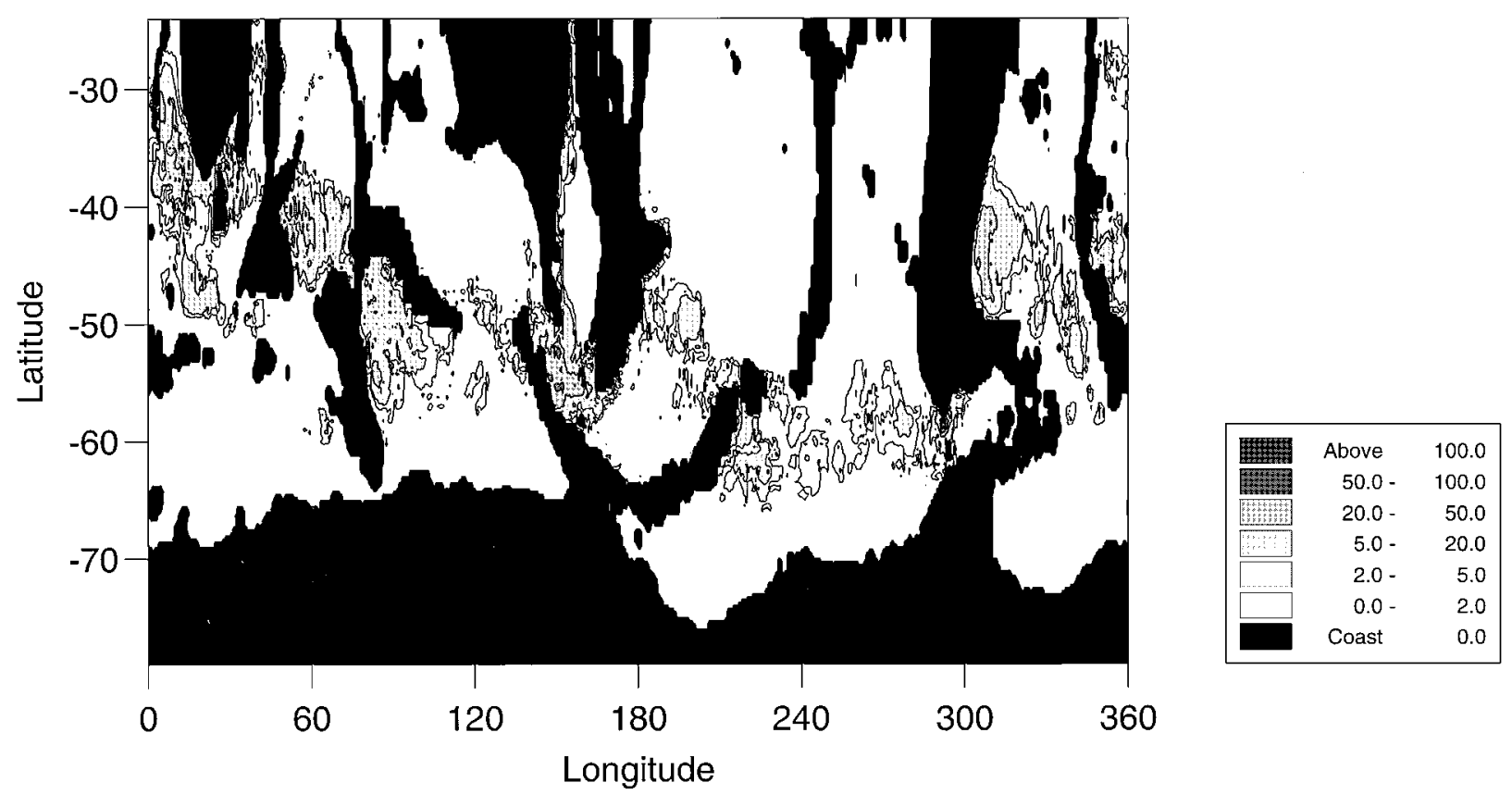

FIG. 4. Eddy kinetic energy (depth $3071 \mathrm{~m}$ ), calculated over the last 6 years of the FRAM run. Contours are in units of $\mathrm{cm}^{2} \mathrm{~s}^{-2}$.

\section{The energy cycle}

a. Equations of the kinetic energy budget

The terms of the kinetic energy balance are the wind stress, the exchange with potential energy, frictional sinks, and the internal exchange between the mean and eddy kinetic energy. Calculation of the energy budget for open regions adds further complexity to this analysis since both nonlinear fluxes and pressure fluxes are nonzero across open boundaries. In spite of this complexity all terms of the budget can be calculated independently and provide useful information about their relative importance.

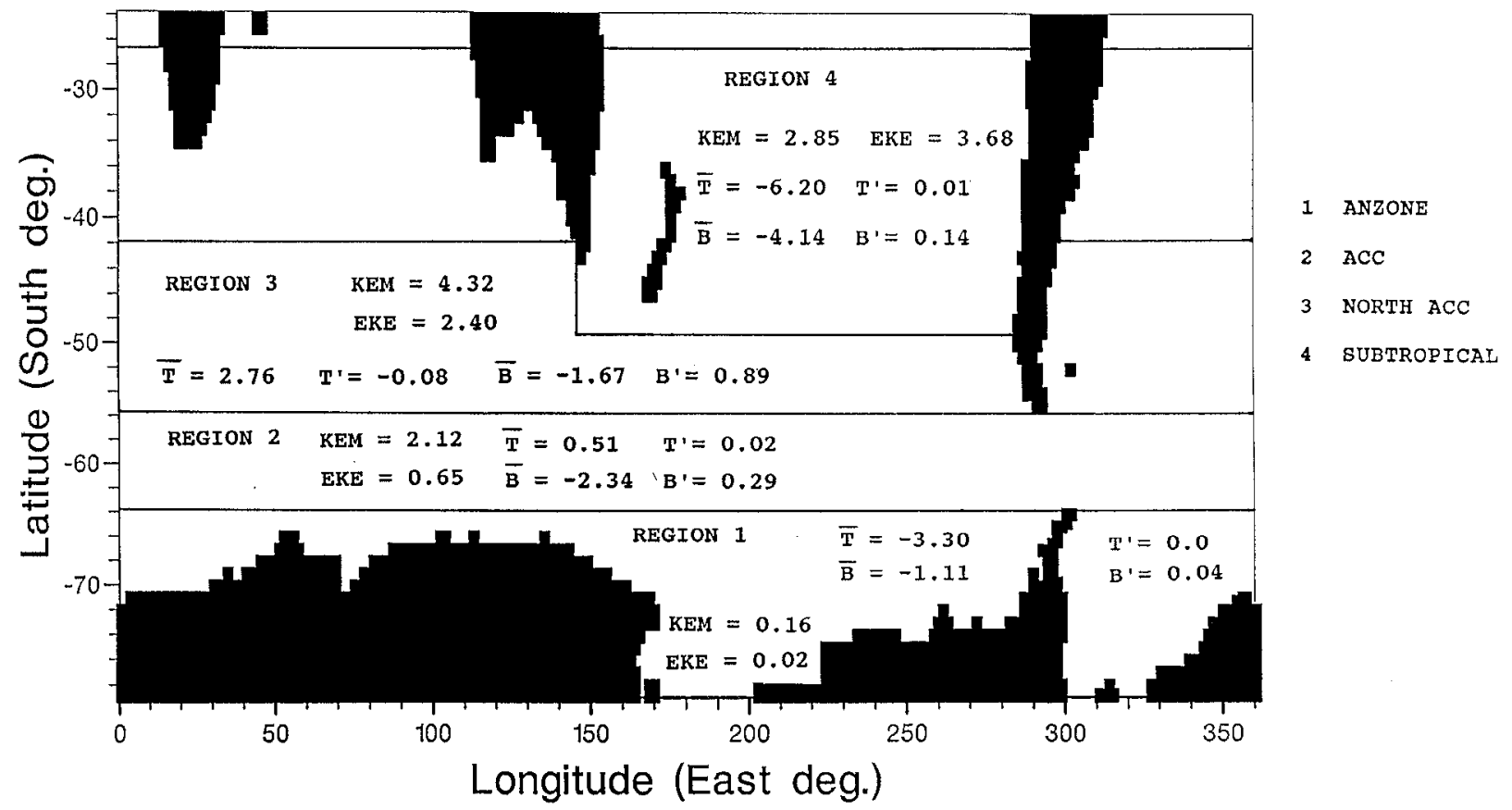

FIG. 5. Regional map for experiment 1 with energy terms in units of $\mathrm{cm}^{2} \mathrm{~s}^{-2}$, and $B$ and $T$ terms in units of $\left(10^{-6} \mathrm{~cm}^{2} \mathrm{~s}^{-3}\right)$. 


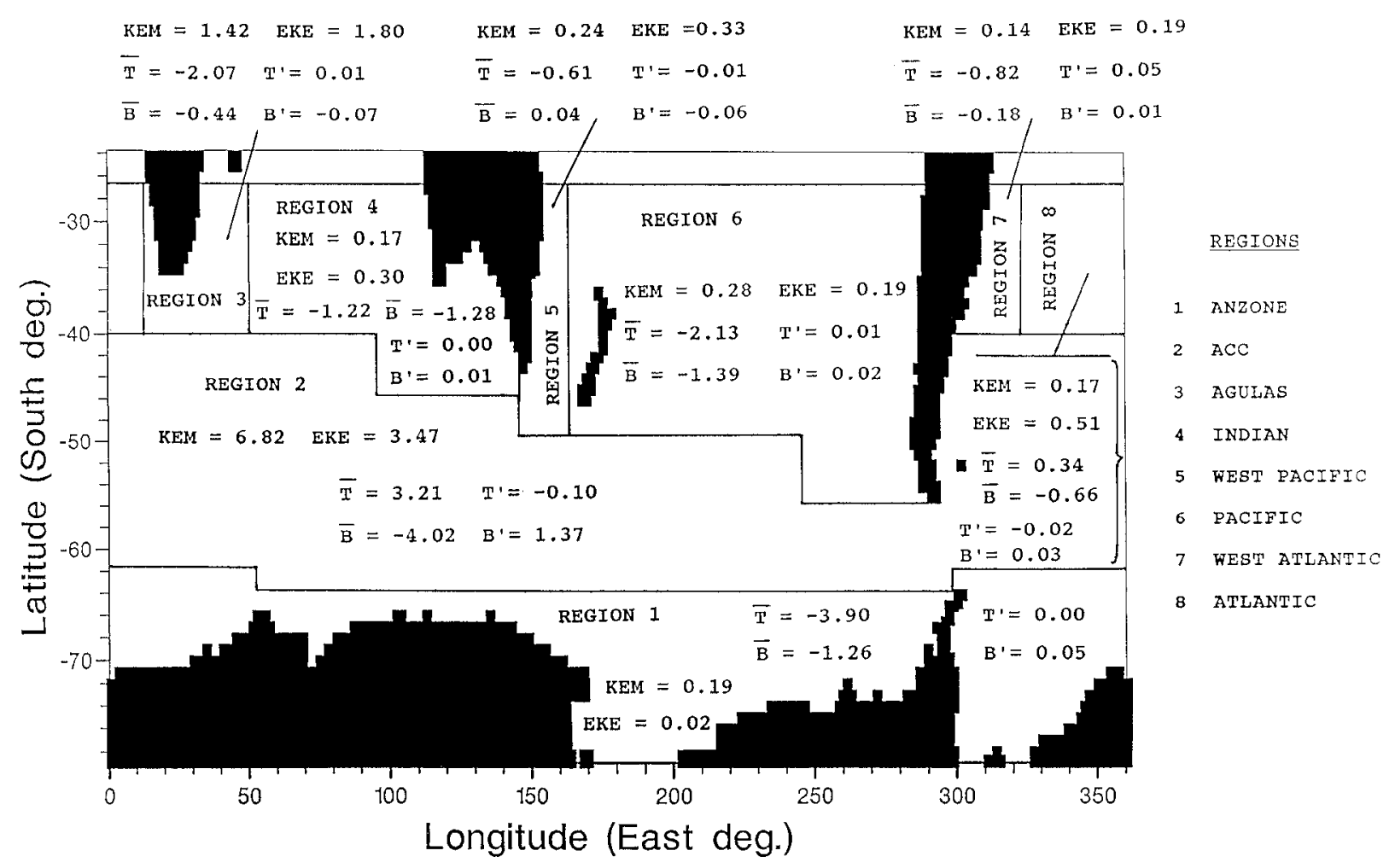

FIG. 6. Regional map for experiment 2 with the same units as for Fig. 5.

The kinetic energy balances for the time-mean flow (KEM) and for the eddies (EKE) are obtained by multiplying the horizontal momentum equations by the time-mean and eddy components of the velocity, respectively. Here the eddy velocity is defined as deviations from the time-mean velocity. Each equation is then integrated over the volume of the region. The equations for KEM and EKE can be written as

$$
\begin{aligned}
& \frac{\partial(\mathrm{KEM})}{\partial t}=\bar{\tau}+\overline{P W}+\bar{N}+\bar{F} \\
& \frac{\partial(\mathrm{EKE})}{\partial t}=\tau^{\prime}+(P W)^{\prime}+N^{\prime}+(F)^{\prime},
\end{aligned}
$$

where overbar indicates time-mean and prime indicates transient eddy terms. The wind stress is represented by $\tau$ and the friction $F$ is the sum of the horizontal friction $F_{H}$, the vertical friction $F_{V}$, and the bottom friction $F_{B}$.

The pressure work terms are

$$
\begin{aligned}
\overline{P W} & =-\frac{1}{\rho_{0}} \int_{(V)} \overline{u_{m}} \frac{\partial \bar{p}}{\partial x_{m}} d V \\
(P W)^{\prime} & =-\frac{1}{\rho_{0}} \int_{(V)} \overline{u_{m}^{\prime} \frac{\partial p^{\prime}}{\partial x_{m}}} d V,
\end{aligned}
$$

where $V$ is the volume, $u_{\mathrm{m}}$ the horizontal velocity components, and $p$ is the pressure. The Cartesian tensor notation is used for simplicity of expression; the index $m=1,2$ represents the horizontal directions while index $j=1,2,3$ represents both horizontal and vertical directions. Summation over repeated indices is implied.

Both $\overline{\mathrm{PW}}$ and $\mathrm{PE}^{\prime}$ can be written as the sum of a buoyancy term $B$ (representing exchanges between potential and kinetic energy) and a pressure flux term $\pi$. Thus,

$$
\begin{aligned}
\overline{P W} & =\bar{B}+\bar{\pi} \\
\bar{B} & =-\frac{g}{\rho_{0}} \int_{(V)} \bar{u}_{3} \bar{\rho} d V \\
\bar{\pi} & =-\frac{1}{\rho_{0}} \int_{(V)} \frac{\partial}{\partial x_{j}} \bar{p} \bar{u}_{j} d V \\
& =-\frac{1}{\rho_{0}} \int_{(A)} \bar{p} \bar{u}_{j} d A_{j},
\end{aligned}
$$

where $A$ is the boundary of the region and $d A$ is the oriented surface element normal to this boundary, $u_{3}$ is the vertical velocity, and $\rho$ is the density. The definitions of $B^{\prime}$ and $\pi^{\prime}$ are similar. The pressure flux terms, $\pi$ and $\pi^{\prime}$, are zero if the volume integration is performed over a closed basin.

The nonlinear term $\bar{N}$ is defined by 


$$
\begin{aligned}
\bar{N} & =\bar{N}_{M}+\bar{N}_{R} \\
\bar{N}_{M} & =-\int_{(V)} \bar{u}_{m} \bar{u}_{j} \frac{\partial \bar{u}_{m}}{\partial x_{j}} d V \\
\bar{N}_{R} & =-\int_{(V)} \overline{u_{m}} \overline{u_{j}^{\prime}} \frac{\partial u_{m}^{\prime}}{\partial x_{j}} d V .
\end{aligned}
$$

Note that $\bar{N}_{M}$ and $\bar{N}_{R}$ can be transformed into the following flux terms:

$$
\bar{N}_{M}=-\int_{(A)} \frac{{\overline{u_{m}}}^{2}}{2} \bar{u}_{j} d A_{j}
$$

and

$$
\begin{aligned}
\bar{N}_{R} & =\int_{(V)} \overline{u_{m}^{\prime} u_{j}^{\prime}} \frac{\partial \overline{u_{m}}}{\partial x_{j}} d V+\mathcal{F} \\
\mathcal{F} & =-\int_{(A)} \overline{u_{m}} \overline{u_{m}^{\prime} u_{j}^{\prime}} d A_{j} .
\end{aligned}
$$

The term $\bar{N}_{M}$ represents the advection of mean flow kinetic energy through the boundary. The first term on the rhs of (7) represents the Reynolds stress work; the same term appears with the opposite sign in the definition of the nonlinear eddy term, $N^{\prime}$, and therefore it represents an exchange between mean and eddy kinetic energy. $\mathcal{F}$ is the eddy-mean flow interaction work at the boundary (see Harrison and Robinson 1978; Treguier 1992, hereafter T92).

The kinetic energy analysis uses the code developed by T92, which is based on the standard energy analysis built into the GFDL code but allows for the separation of time-mean and eddy terms. Treguier has examined kinetic energy budgets in the CME (WOCE Community Model Experiment) model of the North Atlantic. This model, based on the GFDL code has a spatial resolution of $2 / 5^{\circ}$ longitude by $1 / 3^{\circ}$ latitude and covers the Atlantic Ocean from $15^{\circ} \mathrm{S}$ to $65^{\circ} \mathrm{N}$ (Bryan and Holland 1989). The CME energy cycle can be compared with the FRAM analysis. In the present study, the FRAM balances are estimated using a monthly dump dataset. There is very little difference between 1-day, 10-day, and 30-day sampling. For example, 1-day sampling has an energy $1 \%$ or $2 \%$ greater than the monthly and 10-day dumps, which are virtually identical (D. Stevens 1995, personal communication).

\section{b. Choice of a reference density field}

It is well known that in stratified rotating fluids, like the ocean and the atmosphere, the total potential energy is not meaningful. The dynamically relevant quantity is the available potential energy (Lorenz 1955), which is often defined as the difference between the observed potential energy and the potential energy of the same fluid rearranged adiabatically in such a way that the isopycnal surfaces are flat. The available potential en- ergy (APE) is several orders of magnitude smaller than the total potential energy. Because the equation of state for the ocean is nonlinear, it is impossible to write a strict formula for the APE in the ocean. However, it is possible to estimate it using the following equation (Oort et al. 1989; Böning and Budich 1992):

$$
\mathrm{APE}=-\frac{g}{2 V} \int_{(V)} \frac{(\rho-\tilde{\rho})^{2}}{d \tilde{\rho}_{p} / d z} d V,
$$

where $\tilde{\rho}(z)$ is a depth-dependent reference density and $\tilde{\rho}_{p}(z)$ is the potential density of that reference state.

There are a few terms in the kinetic energy balance that depend upon the choice of a reference density. The pressure work terms PW do not because they are proportional to horizontal gradients of density. However, in this analysis pressure work terms have been expressed as the sum of the pressure flux $\pi$ and the buoyancy term $B$. Furthermore, another term appears when the total budget is split into an external mode (depth averaged) and an internal mode (deviation from the depth average). This topographic transfer term, $T$ (defined in the appendix), is nonzero only in the presence of topography. It represents an exchange of energy between the external and internal modes (Holland 1975; T92). Unlike the pressure work terms, the time-averaged buoyancy $\bar{B}$, the topographic exchange $\bar{T}$, and the pressure fluxes all change when a constant is added to the density field.

In order to gain a consistent view of the energy cycle the same reference density must be used to calculate both available potential energy and energy exchange terms. The most usual definition of $\tilde{\rho}(z)$ is simply an horizontal average over the domain considered. P. Rhines (1995, personal communication) has suggested that the most suitable reference density is that which provides a minimum value for the conversion between kinetic and potential energy (i.e., $\bar{B}$ should be a minimum).

Two choices of reference density have been considered: First, a constant value calculated from the volume integral of the density over the whole domain and, second, a reference density averaged horizontally over the whole domain at each model depth level. The former solution has been used by T92, but for FRAM we find it gives values of $\bar{B}$ and $\bar{T}$ two orders of magnitude greater than all the other terms. We therefore prefer the latter solution, which ensures that $\bar{B}$ and $\bar{T}$ are of the same magnitude as the other terms in the balance. Finally, note that the eddy parts of $T$ and $B$ (i.e., $B^{\prime}, T^{\prime}$ ) are independent of the reference density field.

\section{c. The global kinetic energy balance}

Oort et al. (1994, hereafter O94) have attempted to calculate the energy cycle of the World Ocean from observations. L. Anderson has kindly provided estimates of their energy balance terms made from these observations. These terms have been integrated over the Southern Ocean (south of $30^{\circ} \mathrm{S}$ ) and so can be compared with the corresponding FRAM terms. 
TABLE 1 . Energy cycle of the ocean south of $30^{\circ} \mathrm{S}$. The observations are taken from Oort et al. (1994).

\begin{tabular}{lcc}
\hline \hline & $\begin{array}{c}\text { Obser- } \\
\text { vations }\end{array}$ & FRAM \\
\hline Energy per unit area $\left(10^{5} \mathrm{~J} \mathrm{~m}^{-2}\right)$ & 0.07 & 0.06 \\
Kinetic energy (KE) & 5.6 & 59 \\
Available potential energy (APE) & & \\
Energy transfers per unit area (mW m & \\
Wind forcing of KE & 8.1 & 4.0 \\
APE to KE transfer $\bar{B}$ & -0.1 & -2.9 \\
Buoyancy forcing of APE & 0.3 & -4.1 \\
\hline
\end{tabular}

Both 094 and FRAM (see Table 1) show that in the ocean the kinetic energy is much smaller than the available potential energy, in contrast with the atmosphere. Oort et al. estimate kinetic energy by extrapolating surface currents downward, and these estimates give values that are of the same order of magnitude as FRAM. There is not such good agreement for the APE, which is found to be more than an order of magnitude greater in FRAM than in O94. The two estimates are not directly comparable, however, because the reference densities are different. Oort et al. use an average over the World Ocean, while we use the temporally and spatially averaged density in the model domain south of $26.5^{\circ} \mathrm{S}$. The reference state of $\mathrm{O} 94$ is more stratified (that is, $d \tilde{\rho}_{p} / d z$ is larger); hence (8) leads to a lower APE. Furthermore, the 094 estimate does not take into account ice-covered areas and it is based on the top $1000 \mathrm{~m}$ of the ocean only.

In the 094 study, the wind stress forcing is calculated using the same Hellerman wind data as FRAM and surface currents from ship drift. These currents are much smoother than the actual surface currents in FRAM and are probably too well correlated with the wind field, resulting in a higher forcing estimate. The forcing has a large seasonal cycle in 094 (their Fig. 16) due to the seasonal cycle of the ship drift currents. This may be an artifact; the time-varying component of the wind generation is negligible in FRAM.

An important question concerning the energy cycle of the Southern Ocean is the relative part played by wind forcing and surface buoyancy forcing. Oort et al. suggest that the wind forcing is largely dominant. It is not possible to use FRAM results to confirm this hypothesis because the definition of available potential energy and buoyancy forcing is domain dependent. In contrast to O94, there seems to be a net loss of APE through buoyancy forcing in FRAM (Table 1) because of the surface reference density used $\left(1.0267 \mathrm{~g} \mathrm{~cm}^{-3}\right.$ in FRAM and $1.0240 \mathrm{~g} \mathrm{~cm}^{-3}$ for O94). If we used the 094 value of the reference density, FRAM would also give a buoyancy forcing term that is positive. The buoyancy forcing of APE can be estimated as the product of heat and freshwater fluxes by the difference between the reference density and the actual surface density $(\tilde{\rho}-\rho)$, divided by stability [094, Eq. (4)]. In O94, the density south of $30^{\circ} \mathrm{S}$ is everywhere larger than the reference density so that the cooling in the Indian and Pacific Oceans results in a positive forcing of APE (O94, Fig. 5). In FRAM the density is smaller than the reference density north of the ACC region so that the same cooling results in a negative forcing for APE. This shows that wind and buoyancy forcing over an open region are not directly comparable. The forcing of APE through surface buoyancy fluxes depends on the reference density, as does the flux of APE through the open boundaries of the region. The APE forcing calculated with a World Ocean reference density is probably the most meaningful. FRAM confirms the order of magnitude of the wind forcing estimated by 094 , leading further support to the hypothesis that the wind energy input is dominant over buoyancy forcing. However, more precise estimates of air-sea fluxes in the Southern Ocean are necessary to confirm this view.

The most important result in Table 1 is the large conversion of kinetic energy into available potential energy (its magnitude is $75 \%$ of the wind stress forcing). Although we think that the transfer term $\bar{B}$ is dependent on the reference density, we suggest that the FRAM estimate has the correct order of magnitude because the pressure fluxes at the boundary (Fig. 7a) are small (with a magnitude of only $10 \%$ of the wind stress forcing). This conversion is due to the wind-forced upwelling in the ACC. Oort et al. largely underestimated this term by assuming that the Ekman pumping affects only the upper $100 \mathrm{~m}$, whereas positive vertical velocities are found over most of the depth of the ACC (3000 m). According to O94, numerical models give conflicting results regarding the direction of the $\bar{B}$ transfer term. This is not true for eddy-resolving models, however, where it always seems to appear as a source of available potential energy. The buoyancy term is especially large in the Southern Ocean compared with other regions. For example, in the CME2 North Atlantic model $B$ is found to be almost 10 times smaller than in FRAM (Figs. 7a,b). Treguier (1992) has shown this conversion is actually a small difference between large negative values in the western Atlantic and large positive values in the eastern Atlantic, while in FRAM the conversion is from kinetic to potential energy almost everywhere. This demonstrates that in the Southern Ocean the work done by the wind is important in maintaining the meridional density gradients.

Friction terms can be calculated exactly in FRAM, whereas they had to be estimated as residuals in 094 . A more detailed balance for kinetic energy (eddy and mean) is shown in Fig. 7, together with a similar diagram for the CME2 experiment reproduced from T92 for comparison. Note that the units differ from Table 1.

The main frictional kinetic energy sink in FRAM is lateral friction, whereas vertical friction is more important in CME2. This is not surprising, because the vertical viscosity coefficient is 10 times smaller in FRAM, and moreover T92 shows that vertical friction 


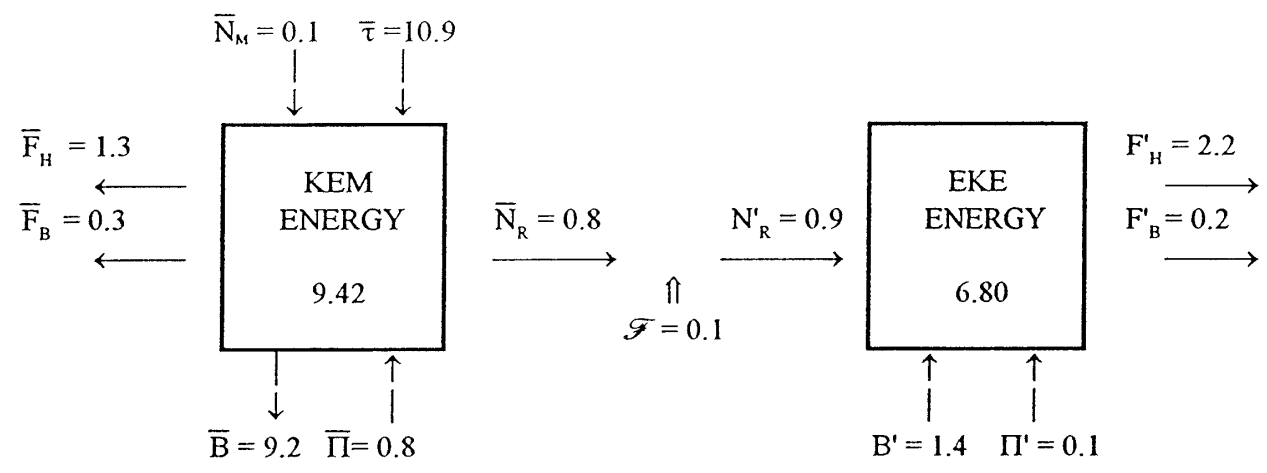

CME2 DOMAIN

KEM/EKE SPLIT

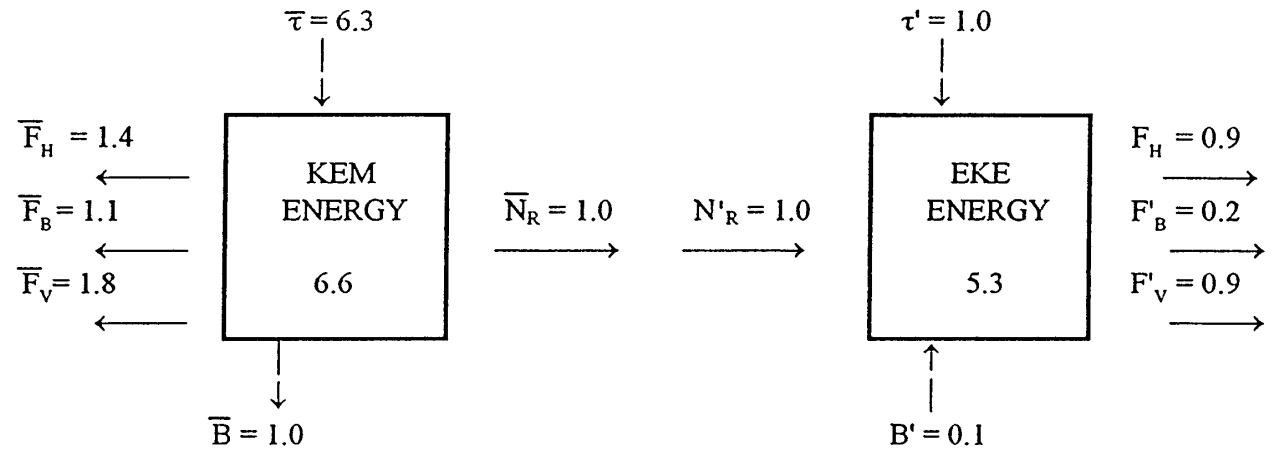

FIG. 7. Total domain energy balance for the time-mean and eddy kinetic energy. All values are integrated over the domain and divided by the total domain volume. Here $\overline{N_{R}}$ and $N^{\prime}{ }_{R}$ represent nonlinear kinetic energy transfer between KEM and EKE, and $\mathcal{F}$ is the nonlinear flux across an open boundary. Units are in $\mathrm{cm}^{2} \mathrm{~s}^{-2}$ for energy levels and in $10^{-6} \mathrm{~cm}^{2} \mathrm{~s}^{-3}$ for energy transfers. (a) The FRAM experiment; (b) The CME2 experiment from T92.

is important mainly in low latitude regions of the CME2. The repartition between the various friction terms in FRAM is not very different from the northern regions of the CME2 experiment (T92, Fig. 9). Of the total work done by the wind stress in FRAM, around $77 \%$ of this occurs in the ACC region (expt 2) as does $71 \%$ of the sink due to horizontal friction.

The diagrams of Fig. 7, which separates transient and mean kinetic energy, and Fig. 8, where the external and internal modes are separated, will be used to contrast the dynamics and instability processes in FRAM and CME2. Before that, let us discuss the boundary flux terms appearing in these figures. It is rather encouraging that the artificial boundary condition does not represent a significant source or sink of eddy variability in Fig. 7. On the other hand, the pressure fluxes at the boundary generate a large energy exchange between the barotropic and baroclinic energy (Fig. 8). This could be expected since the barotropic mode is forced by Sverdrup dynamics while there are only radiation conditions on the baroclinic flow (D. Stevens 1995, personal communication). The large value of the pressure flux (of a magnitude similar to the wind stress) could indicate that the boundary forcing has a large influence on the model. On the other hand, since pressure fluxes depend on the choice of the reference density, it is not clear whether their amplitude is significant. The pressure flux is a source of barotropic energy, but only in the northern 


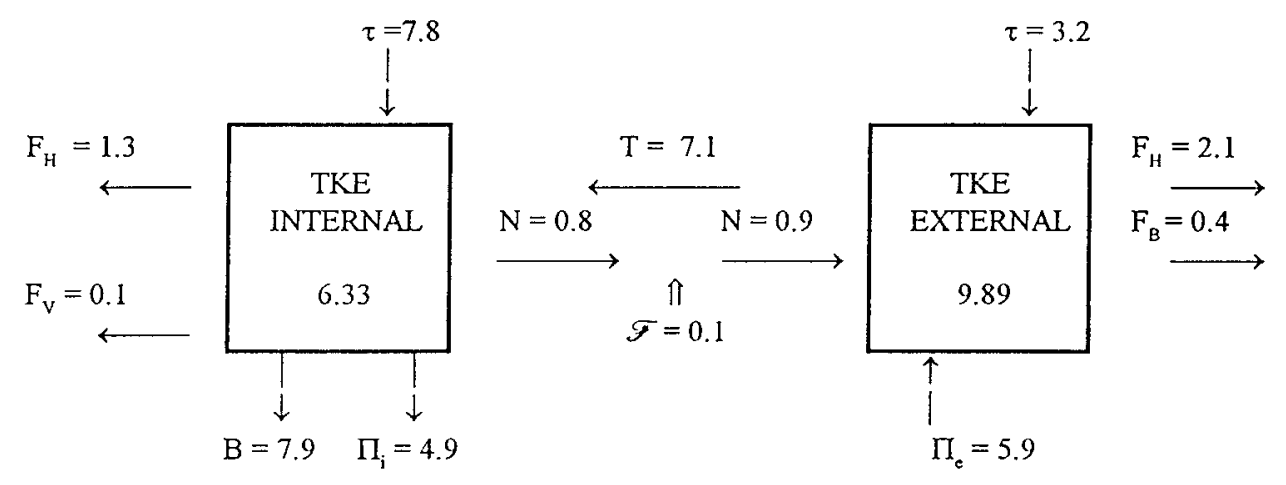

CME2 DOMAIN

INTERNAL/ EXTERNAL SPLIT

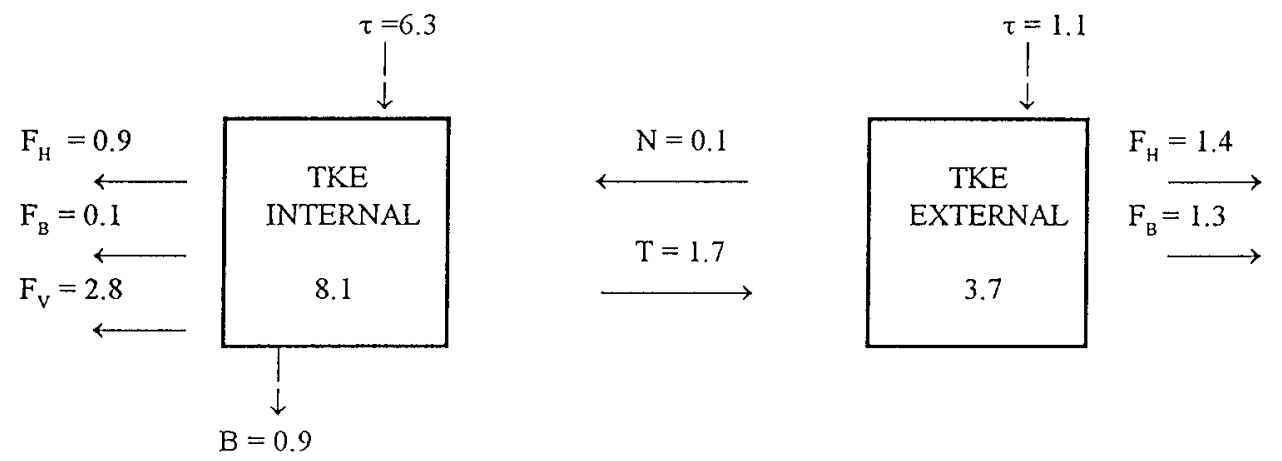

FIG. 8. Total domain energy balance for the internal and external mode energy. $N$ and $\mathcal{F}$ represent nonlinear kinetic energy transfer between external and internal modes and the nonlinear flux across an open boundary, respectively. Units as in Fig. 7. (a) The FRAM experiment; (b) CME2 experiment.

(subtropical) region. In the ACC the pressure fluxes are a sink of barotropic energy. Therefore, we are confident that the dynamics of the ACC in FRAM can be discussed independently of the boundary fluxes.

\section{d. The specificity of channel dynamics}

The dynamics of zonal channel flow and closed-basin (gyre type) flow are very different. In a zonal channel, the ambient vorticity $f / H$ contours are not blocked in the upper layers and allow continuous flow in the absence of friction and forcing. Unlike the closed-basin case no Sverdrup balance can be established above the topography, and this affects the instability processes. In closed basins strong zonal gradients are imposed by the walls and eddy generation tends to be more localized. The areas of eddy decay in closed basins are extensive (Marshall 1981), and in these areas the eddy fluxes of potential vorticity are no longer downgradient.

The Southern Ocean comprises not only the quasizonal ACC, but also several gyres. Even the ACC does not have exactly zonal flow; in several places there are huge meridional displacements of the current. In this section we assess the relative importance of channel and closed-basin dynamics as revealed by the energy balances.

Let us first consider the energy balance for the external and internal modes (Fig. 8). In FRAM the external 
EXPT 2 : ACC REGION

KEM/EKE SPLIT

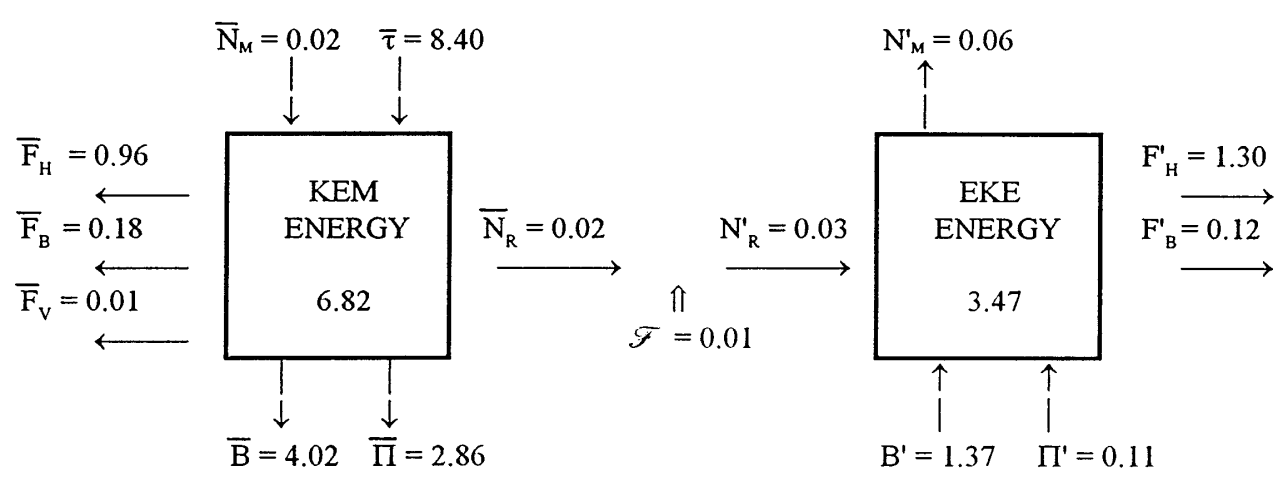

FIG. 9. ACC region (expt 2) energy balance for the time-mean and eddy kinetic energy. Terms and units as in Fig. 7.

mode has 1.6 times more kinetic energy than the internal mode, whereas in the CME2 experiment the internal mode is dominant. Quasigeostrophic channel models have an even greater difference between the external and internal mode (the barotropic kinetic energy is about an order of magnitude larger than the baroclinic one). The barotropic character of FRAM is partially due to the low stratification since the northern regions in the CME2 experiment also tend to have a larger fraction of barotropic kinetic energy. However, it is also a consequence of channel dynamics because regions with channel geometry like the ACCB have relatively more barotropic kinetic energy than gyre-type regions. This is also reflected in experiment 2, where the ACC region has twice as much energy in the external mode as in the internal mode. In all other regions the reverse is the case.

The barotropic character of channel flows comes from the wind stress work, which is more efficient in a periodic geometry since it cannot be balanced by a pressure gradient. In the CME the external mode forcing was only $16 \%$ of the internal mode forcing, whereas in FRAM it is $40 \%$ for the global domain and $53 \%$ for the ACC region only.

Nonlinear transfer from the internal to external mode makes a significant contribution to the barotropic mode in FRAM. This nonlinear exchange occurs almost exclusively in the ACC region (expt 2). This agrees with QG channel experiments and may be explained by the concept of inverse cascade in the vertical direction (Charney 1971; T92). Such a nonlinear generation of barotropic energy can also result from baroclinic instability mechanisms. In the CME2 experiment the nonlinear transfer is much smaller than in FRAM, most probably because the generation of eddies by baroclinic instability is significantly less in CME2 than in FRAM.

A last source of barotropic energy in the ACC region is the topographic term $\bar{T}$, although it is in the opposite direction for the total domain (Fig. 8). In both the FRAM and CME2 models the sign of $\bar{T}$ varies from one region to the other; the significance of the domain-averaged value is therefore open to question. Topography is often viewed as a source of mean barotropic transport through the so-called JEBAR (joint effect of baroclinicity and bottom relief) effect. It may be shown that JEBAR is related to $T$ (see the appendix). Depending on the correlation between the JEBAR effect and the barotropic streamfunction, the net effect can be a source or a sink of external mode energy. In FRAM, $\bar{T}$ is a source of mean external mode energy in the ACC region although the opposite transfer occurs in the northern and southern regions. The $\bar{T}$ term indicates that the topography has a large effect on the vertical structure of the mean flow. However, it is not certain that this effect can be interpreted locally in the energy balance.

Topography can also affect the transients. In quasigeostrophic models it tends to make turbulence more baroclinic (Rhines 1977), and therefore $T^{\prime}$ is generally negative (energy transfer from the external to the internal modes). However, in FRAM (as was the case for CME2) $T^{\prime}$ is found to be small.

Besides the strongly barotropic character of the flow, another characteristic revealed by the energy balances is the predominance of the buoyancy transfer, $B^{\prime}$, as a source of eddy energy. In numerical models for closed basins the nonlinear conversion $N_{R}^{\prime}$ from KEM to EKE is usually greater than $B^{\prime}$. For example, in the CME2 experiment $N_{R}^{\prime} / B^{\prime}=10$, while in quasigeostrophic basin experiments $N_{R}^{\prime} / B^{\prime}$ may range from 2 to 38 (Fig. 8 of 
TABLE 2. Energy and energy transfer terms for experiment 1.

\begin{tabular}{lccccc}
\hline \hline Expt 1 & EKE & PEM & EPE & $\begin{array}{c}A^{\prime} \\
\left(\times 10^{-6}\right)\end{array}$ & $\begin{array}{c}B^{\prime} \\
\left(\times 10^{-6}\right)\end{array}$ \\
\hline Anzone & 0.3 & 2408 & 14.6 & 0.3 & 0.6 \\
ACCB & 3.6 & 6773 & 45.4 & 5.9 & 1.6 \\
NACC & 9.5 & 4855 & 52.9 & 13.3 & 3.5 \\
SUBTR & 6.4 & 2764 & 38.9 & 4.1 & 0.3 \\
\hline
\end{tabular}

T92). For FRAM this ratio is found to be less than one; that is, $N_{R}^{\prime} / B^{\prime}=0.6$. However, subregions within the total domain were found to have widely varying values, reflecting the different types of dynamics in the model (Figs. 9-11). For example, in the western boundary regions, $N_{R}^{\prime} / B^{\prime}$ is 8 in the Agulhas, 3 in the Westpac region, and 2 in the WestAtl region. For the channeltype regions, the ratios are much less than one; that is, $0.04,0.02$, and 0.02 for ACCB, NACC, and ACC regions respectively. This clearly indicates a significant difference between channel-type regions, where eddy nonlinear transfers are much smaller than the exchange with potential energy, and basin-type regions, where nonlinear terms tend to be greater than the eddy buoyancy exchange $B^{\prime}$.

\section{Instability processes}

\section{a. Global balance for eddy kinetic energy}

The global balance for the kinetic energy of the timemean flow and eddy kinetic energy (hereafter KEM and EKE) provides a first insight into the instability processes (Fig. 7).

The input of energy due to wind stress fluctuations is found to be insignificant when compared with the other terms (e.g., it is only $3 \%$ of the buoyancy term). This may be because the model uses climatological monthly mean wind stresses, which do not include variability on more rapid timescales. Note that although CME2 used the same climatological winds, the eddy wind stress work was larger in CME2 because of the large seasonal response of the ocean in the Tropics.

Lateral friction is the main sink for EKE. It is even greater than the corresponding sink for the mean flow. In CME2, the friction terms are also the main sink for EKE, however, they are about one-half the magnitude of the mean flow friction. The importance of the horizontal friction in FRAM is certainly partly due to the form of parameterization (with FRAM using both Laplacian and biharmonic friction, while CME2 used only biharmonic friction).

The most important sources of energy are the buoyancy term, $B^{\prime}$, and the nonlinear transfer term, $N_{R}^{\prime}$. The eddy buoyancy transfer $B^{\prime}$ is most important in the ACC region. If we consider the regions where $B^{\prime}$ represents a source of EKE (Fig. 6), the proportion generated in the ACC region is $92 \%$. When the ACC is split into the ACCB and NACC (expt 1), the ACCB contributes for
TABLE 3. Energy and energy transfer terms for experiment 2. EKE is the eddy kinetic energy (units: $\mathrm{cm}^{2} \mathrm{~s}^{-2}$ ); PEM is the mean available potential energy (units: $\mathrm{cm}^{2} \mathrm{~s}^{-2}$ ); EPE is the eddy available potential energy (units as PEM); $A^{\prime}$ energy transfer from PEM to EPE (units: $\left.\mathrm{cm}^{2} \mathrm{~s}^{-3}\right) ; B^{\prime}$ energy transfer from EPE to EKE (units as for $A^{\prime}$ ).

\begin{tabular}{lrrrrr}
\hline \hline Expt 2 & EKE & PEM & EPE & $\begin{array}{c}A^{\prime} \\
\left(\times 10^{-6}\right)\end{array}$ & $\begin{array}{c}B^{\prime} \\
\left(\times 10^{-6}\right)\end{array}$ \\
\hline Anzone & 0.2 & 2628 & 13.4 & 0.3 & 0.5 \\
ACC & 8.6 & 6603 & 46.3 & 13.8 & 3.4 \\
Agulhas & 52.3 & 944 & 176.1 & 8.8 & -2.3 \\
Indian & 2.6 & 965 & 39.0 & 2.6 & 0.1 \\
WestPac & 12.8 & 1006 & 65.5 & 9.8 & -2.2 \\
Pacific & 0.8 & 909 & 12.8 & 0.3 & 0.1 \\
WestAtl & 15.0 & 1083 & 111.7 & 9.4 & 1.2 \\
Atlantic & 7.7 & 3979 & 84.3 & 8.0 & 0.4 \\
\hline
\end{tabular}

$24 \%$ and the NACC $76 \%$ of the total. This shows that an analysis restricted to the ACCB region would miss the largest part of the eddy activity in the ACC, giving further support to the analysis of Ivchenko et al. (1996) along the time-mean streamlines.

The nonlinear transfer, $N_{R}^{\prime}$, is a source of eddy energy in all FRAM regions. It may be interpreted as a conversion from KEM to EKE and can be related to barotropic instability processes since the energy flux across the northern boundary is small (Fig. 7a). The sign of this conversion term is the same in all subregions, but a reversed transfer (the "negative viscosity" effect) occurs locally just northeast of Drake Passage. Note that in the ACC the nonlinear transfer $N_{R}^{\prime}$ is small. For example, in experiment 2, the ACC region accounts for less than $4 \%$ of the exchange for the total domain and in the NACC region of experiment $1 N_{R}^{\prime}$ is 28 times smaller than $B^{\prime}$. This may be due to a compensation between barotropic instability (which generates EKE from the mean flow) and negative viscosity effects (which generate mean energy from the eddies) in the ACC. Such a compensation was found in the quasigeostrophic model of Treguier and McWilliams (1990) in the presence of topography.

\section{b. Available potential energy and mean-to-eddy flux}

In this section, baroclinic instability is examined by considering the eddy available potential energy (EPE) and its exchange with the mean potential energy (PEM). Using the approximate form (8), this exchange between PEM and EPE, called $A^{\prime}$, can be estimated as (Böning and Budich 1992)

$$
A^{\prime}=\frac{1}{V} g \int_{(V)} \frac{\left(\overline{u^{\prime} \rho^{\prime}} \frac{\partial \bar{\rho}}{\partial x}+\overline{v^{\prime} \rho^{\prime}} \frac{\partial \bar{\rho}}{\partial y}\right)}{\frac{d \tilde{\rho}_{p}}{d z}} d V .
$$

The results of the available potential energy analysis for experiments 1 and 2 are shown in Tables 2 and 3, respectively. For completeness, the values of EKE and the 
buoyancy energy transfer $B^{\prime}$ are also indicated. All the terms shown in these tables have been averaged over their corresponding regions so that they represent densities for each particular region. This averaging is different from the one used in the previous figures where the integrated terms were normalized by the total domain volume. Averaging to form regional energy densities gives a better indication of the relative strength of instability processes occurring in various regions.

The time-mean available potential energy (PEM) is largest in the ACC regions. It may seem surprising that PEM is similar in the Anzone region and the subtropical region (Table 2) since the subtropical region is much more stratified. The reason for this is that there is a much greater variation of densities in the Anzone region than the subtropical region, and therefore there is a greater difference between these values and the reference density.

Both the EPE density and the $A^{\prime}$ transfer reveal the baroclinically unstable regions. For experiment 1 , these terms are clearly larger in the ACC and subtropical regions compared with their values in the Anzone. Experiment 2 shows that baroclinic instability is an important mechanism in the "western boundary" regions, that is Agulhas, WestPac, and WestAtl.

The comparison between $A^{\prime}$ and $B^{\prime}$ gives further insight into the instability mechanism. In the ACC, $A^{\prime}$ and $B^{\prime}$ have the same sign and are of the same order of magnitude. This is consistent with the classical picture of baroclinic instability whereby EPE and EKE are created out of PEM. Note that the ratio of the $B^{\prime}$ source of EKE in the NACC and the ACCB regions is almost equal to the ratio of their eddy kinetic energy densities. This further suggests that the energy levels in these regions are closely linked with the degree of baroclinic instability occuring in each region. For the Anzone, on the other hand, $B^{\prime}$ is larger than $A^{\prime}$, which clearly means that the source of eddy kinetic energy is not linked completely to baroclinic instability.

The picture is more complicated in the western boundary regions. The Agulhas region has a high value of EKE density (52.2 $\mathrm{cm}^{2} \mathrm{~s}^{-2}$, Table 3), but its source is apparently an energy transfer from KEM (barotropic instability) since the $B^{\prime}$ flux, which is not insignificant, tends to produce a decrease of EKE. A similar situation occurs in the WestPac region. Here EKE is generated principally by a nonlinear transfer from KEM, with the $B^{\prime}$ acting as a sink for EKE. This does not mean that baroclinic instability is not active in these regions, because they also have large values of $A^{\prime}$. The most likely explanation is that different mechanisms interact, that is, local baroclinic instability processes and also exchanges of kinetic and potential energy with neighboring regions.

\section{c. Instability analysis}

We have also tried to assess the degree of baroclinic instability of the flow by finding the baroclinically un- stable modes of the spatially averaged and time-averaged zonal shear $\bar{u}(z)$. The spatial averaging has been made in several areas of length between $10^{\circ}$ and $20^{\circ}$ longitude and width of $5^{\circ}$ latitude. The selected areas cover a broad range of latitudes and kinetic energy levels, and all of them have predominantly zonal mean flow (where the averaged $\bar{v}$ is small compared with $\bar{u}$ below the surface Ekman layer). The instability analysis follows Beckmann (1988). We assume the shear is uniform in latitude and have used the quasigeostrophic approximation to allow separation of the horizontal and vertical dimensions. The equation solved for unstable modes is similar to Beckmann's Eq. (10), with Laplacian and biharmonic friction taken into account. The equation is discretized vertically using the same vertical grid as the FRAM model.

In all the regions considered, the flow has been found to be baroclinically unstable. The growth rates are typically 50 day $^{-1}$ and range from 12 day $^{-1}$ for tight jets within the ACC to 68 day $^{-1}$ in broader flow. Regions with the largest shear have both the highest growth rates and highest eddy kinetic energy density. The growth rate is maximum for scales 2 to 3 times larger than the local Rossby radius. Since the Rossby radius wavelength varies from $2 \pi 8 \mathrm{~km}$ to $2 \pi 20 \mathrm{~km}$, unstable wavelengths are therefore between 125 and $400 \mathrm{~km}$. Note that in most regions these unstable wavelengths are marginally resolved by the zonal grid spacing, which is 30 $\mathrm{km}$ in the southern latitudes and $40 \mathrm{~km}$ at $45^{\circ} \mathrm{S}$. The most unstable modes are surface-intensified with a vertical structure similar to that of the first baroclinic mode.

A typical picture of growth rate as a function of wavenumber is shown for a region to the northeast of Drake Passage (Fig.12). The long wavelengths are stable because of the $\beta$ effect, while the short wavelengths are stabilized by friction. This is demonstrated by Fig. 12b, which shows the growth rates calculated without lateral friction. The effect of friction in midlatitude regions is to decrease the maximum growth rate (by about a factor of 3). At higher latitudes, friction also shifts the most unstable wavelength toward larger scales, as shown in Fig. 13.

\section{Conclusions}

The energy analysis presented here confirms that the dynamics of the FRAM model are broadly consistent with both theories and results from quasigeostrophic channel models of the ACC.

The main source of time-mean kinetic energy is the wind stress, with the buoyancy transfer to potential energy providing the main sink. This result supports the view that the ACC is mainly a wind-driven current and that the wind stress forcing in the Southern Ocean may have an important influence on the global thermohaline circulation (Toggweiler and Samuels 1995). Using climatological monthly mean wind stress values, the generation of eddy kinetic energy by the wind stress is 


\section{EXPT 2 : AGULHAS REGION}

KEM/EKE SPLIT

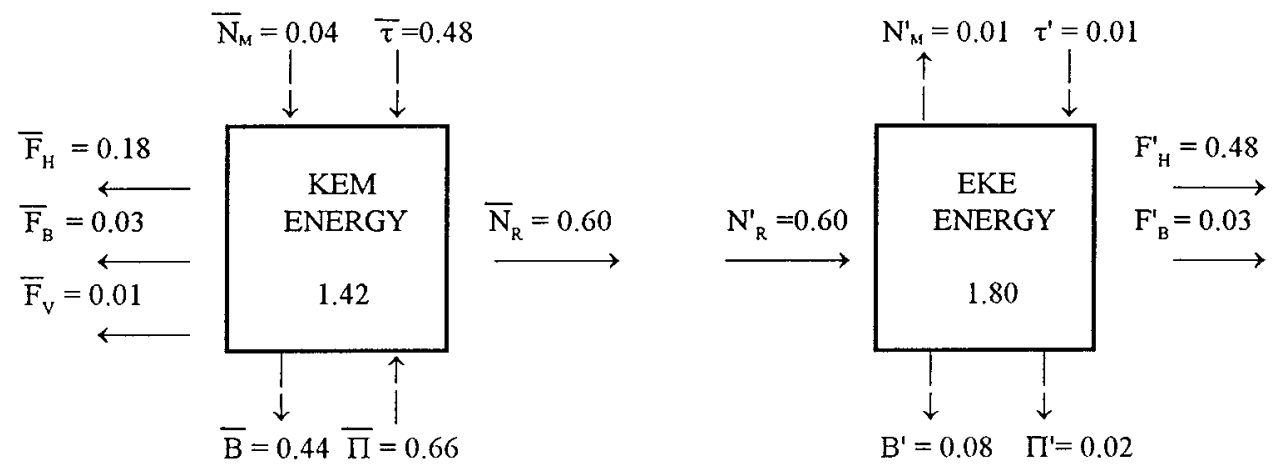

FIG. 10. Agulhas region (expt 2) energy balance for the time-mean and eddy kinetic energy. Terms and units as in Fig. 7.

found to be negligible so that eddy activity results solely from internal instabilities.

A comparison of the present analysis with a similar study of the North Atlantic CME2 model shows that FRAM has more energy in the barotropic mode. This reflects the expected difference between a zonal channel flow compared with gyre-type flows. The barotropic mode in FRAM is efficiently forced by the wind stress as well as by the nonlinear conversion from baroclinic to barotropic kinetic energy.

As expected, baroclinic instability is found to be the most important source of eddy kinetic energy. The highest values for the conversion between mean available potential energy and eddy available potential energy occur in the western boundary regions, the Agulhas and in the ACC, especially on its northern flank. The instability analysis of areas of zonal flow show that the flow is baroclinically unstable everywhere, with typical growth rates of $50 \mathrm{day}^{-1}$.

Our results show that the deficit of eddy kinetic energy in FRAM does not result from an absence of baroclinic instability, but rather from friction that is too high. Since the friction coefficients in FRAM were chosen in order to ensure numerical stability, a decrease in friction will only be possible with higher horizontal resolution. From Fig. 13 it can be seen that a grid of 10 to $15 \mathrm{~km}$ would be needed to resolve the most unstable wavelength at $57^{\circ} \mathrm{S}$ : this is 2 to 3 times smaller than the FRAM grid.

The nonlinear transfer from the mean to eddy kinetic

EXPTI : ACCB REGION : KEM/EKE SPLIT

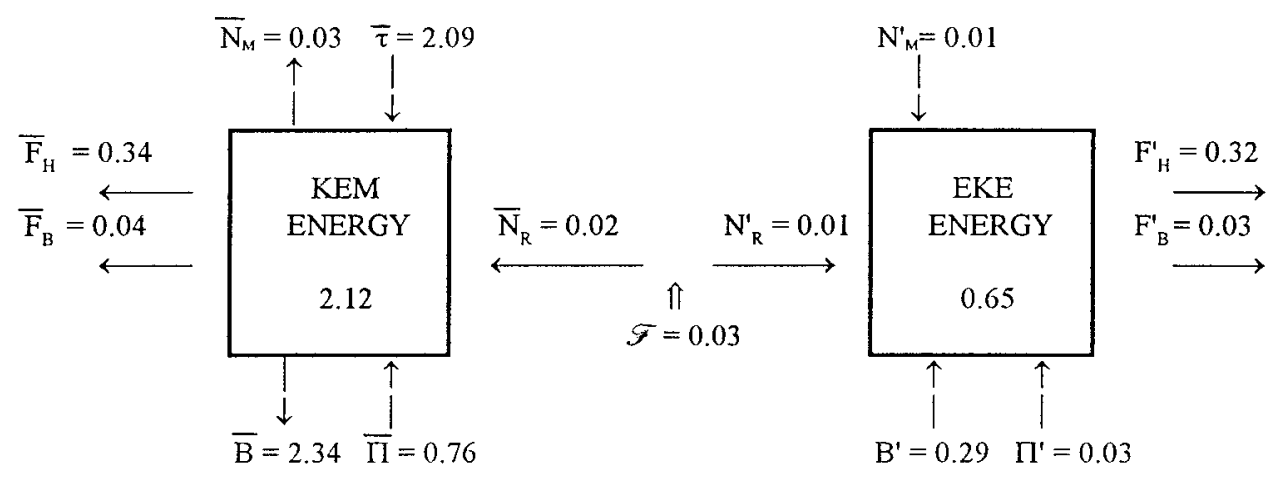

Fig. 11. ACC Belt (expt 1) region energy balance for the time-mean and eddy kinetic energy. Terms and units as in Fig. 7. 

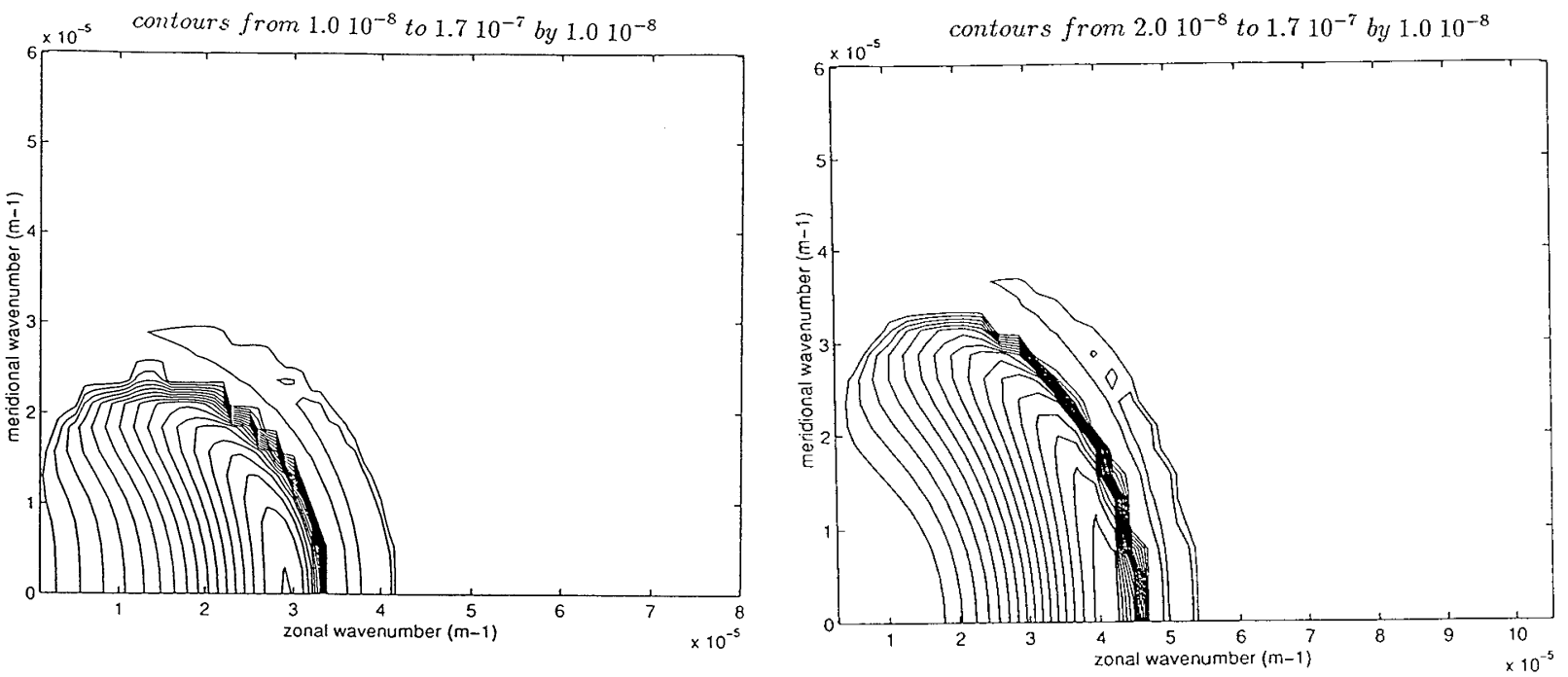

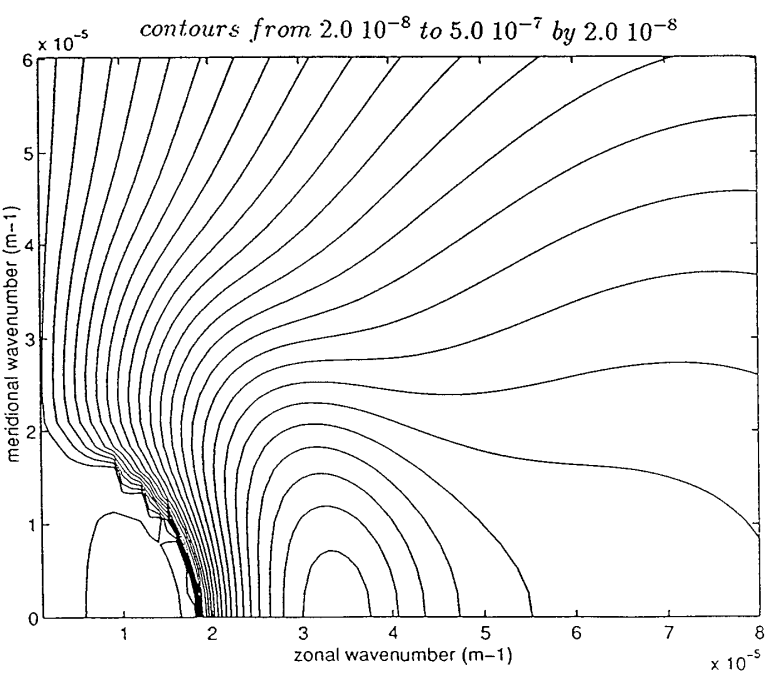

FIG. 12. Growth rate as a function of wavenumber for a region between $42.25^{\circ}$ and $47.25^{\circ} \mathrm{S}, 47.5^{\circ}$ and $27.5^{\circ} \mathrm{W}$. (a) With lateral friction. The maximum growth is $1.7 \times 10^{-7} \mathrm{~s}^{-1}=68$ day $^{-1}$. (b) Without lateral friction. The maximum growth is $4.9 \times 10^{-7} \mathrm{~s}^{-1}=24 \mathrm{day}^{-1}$.

energy, which we interpret as a barotropic instability, is also important in the total domain balance. This transfer occurs from KEM to EKE in every subdomain; the reverse transfer, or "negative viscosity," is found in none of the subregions considered here. It is noted that FRAM did exhibit the negative viscosity effect in some very local tight jets (e.g., just to the northeast of Drake Passage). However, this effect is found to be quite localized and for reasonably large regions it makes no net contribution to the balance. This result agrees with the relatively small Reynolds stresses found in the momentum analysis of SI and Ivchenko et al. (1996). It would be interesting to estimate this effect in other Southern Ocean numerical models with a resolution higher than FRAM.

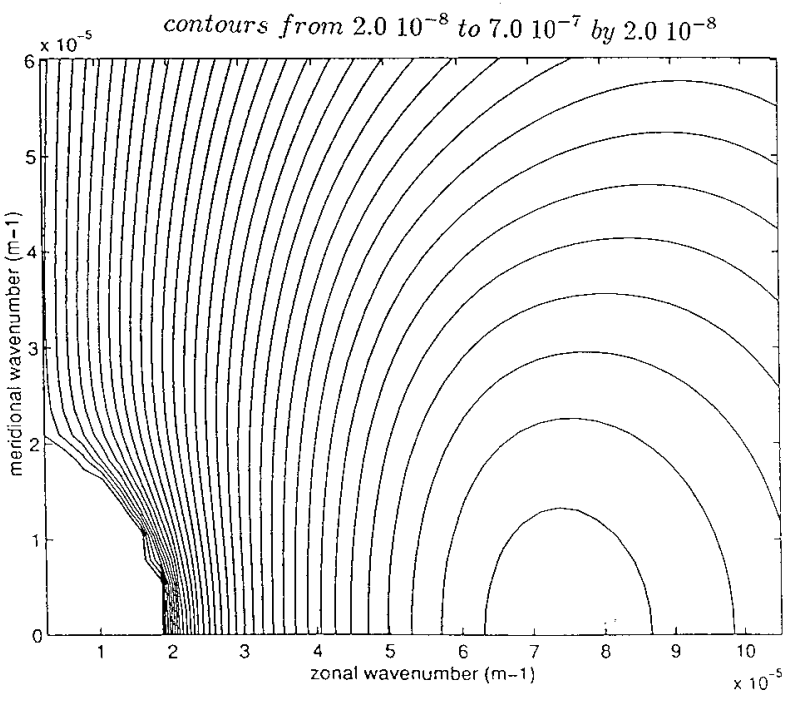

FIG. 13. Growth rate as a function of wavenumber for a region between $60^{\circ}$ and $55^{\circ} \mathrm{S}, 96.75^{\circ}$ and $106.75^{\circ} \mathrm{E}$. (a) With lateral friction. The maximum growth is $1.78 \times 10^{-7} \mathrm{~s}^{-1}=65 \mathrm{day}^{-1}$. (b) Without friction. The maximum growth is $6.9 \times 10^{-7} \mathrm{~s}^{-1}=17$ day $^{-1}$.

Our study also provides a first insight into the influence of the open boundary conditions on the dynamics in FRAM. When averaged over the whole domain, the total energy and pressure fluxes at the northern boundary are small for both the time-mean and eddy balances. However, the open boundary condition seems to induce a large exchange between internal mode and external mode energy. This is certainly due to the fact that the barotropic mode is imposed from a Sverdrup balance without regard for the topography or density field at the northern boundary. The barotropic field is therefore inconsistent, and one would expect some redistribution of energy close to the boundary. This phenomenon cer- 
tainly affects the dynamics of the subtropical regions but, one hopes, not the ACC region (since the pressure flux terms have different signs in the two regions). Further analysis of such open boundary conditions is certainly necessary.

Acknowledgments. We gratefully acknowledge the help and support of the FRAM team in providing the data from the numerical model experiment and in useful discussions, in particular Dr. P. Killworth, Dr. K. Richards, Dr. D. Stevens, Dr. D. Webb, Dr. N. Wells, and Dr. A. Coward. V. O. Ivchenko was supported by the NERC under Grant GST/02/0817, A. M. Treguier was supported by C.N.R.S, and S. Best was supported by a NERC studentship.

\section{APPENDIX}

\section{The Pressure Gradient Work}

The energy budget for the external (i.e., depth-averaged velocity) mode and the internal mode is a useful tool for understanding the ocean dynamics (Holland 1975). In the following, index $i$ refers to the internal mode and $e$ to the external mode. The energy balance of the internal and external mode total kinetic energy (TKE) comprises nonconservative processes (wind stress input, horizontal, vertical, and bottom friction), nonlinear exchange between external and internal modes, and pressure gradient work $\left(\mathrm{PW}_{i}, \mathrm{PW}_{e}\right)$ :

$$
\begin{aligned}
\mathrm{PW}_{e} & =-\int_{(V)} u_{m}^{e} \frac{\partial p}{\partial x_{m}} d V \\
\mathrm{PW}_{i} & =-\int_{(V)} u_{m}^{i} \frac{\partial p}{\partial x_{m}} d V,
\end{aligned}
$$

where $V$ is the volume, $p$ is the pressure, and summation is implied over index $m=1,2$.

The pressure gradient work integrated over a domain is related to the exchange between potential and kinetic energy $B$, a topographic term $T$, and the fluxes $\Pi$ through the open boundaries (T92):

$$
\begin{aligned}
& \mathrm{PW}_{\mathrm{e}}=T+\Pi_{e} \\
& \mathrm{PW}_{i}=B-T+\Pi_{i} .
\end{aligned}
$$

For closed basins the equations become simply

$$
\begin{aligned}
& \mathrm{PW}_{e}=T \\
& \mathrm{PW}_{i}=B-T .
\end{aligned}
$$

The buoyancy term $B$ and topographic exchange $T$ are defined by

$$
\begin{aligned}
& B=-\int_{(V)} u_{3} \rho g d V . \\
& T=-\int_{(S)}\left(p^{e}-p^{b}\right) u_{m}^{e} \frac{\partial H}{\partial x_{m}} d S,
\end{aligned}
$$

with $H$ the ocean depth and $S$ the horizontal surface of the domain.

From the above it can be seen that the topographic transfer term $T$ describes an exchange of energy between the internal and external modes. This mechanism is different from the nonlinear transformation term. The term $T$ is zero for flat-bottom domains, or when the density is constant. The external pressure work $\mathrm{PW}_{e}$ (and therefore $T$ ) is related to the so-called JEBAR effect. JEBAR appears on the right-hand side of the depth-averaged vorticity equation and is usually written

$$
J\left(\chi, \frac{1}{H}\right), \quad \chi=\frac{g}{\rho_{0}} \int_{-H}^{0} z \rho d z .
$$

The external pressure gradient work $\mathrm{PW}_{e}$ is the product of JEBAR by the barotropic streamfunction $\psi$ for the depth-averaged transport

$$
\mathrm{PW}_{e}=-\int_{S} \frac{\psi}{H} J\left(\chi, \frac{1}{H}\right) d S .
$$

\section{REFERENCES}

Beckmann, A., 1988: Vertical structure of midlatitude mesoscale instabilities. J. Phys. Oceanogr., 18, 1354-1371.

_ C. W. Böning, B. Brugge, and D. Stammer, 1994: On the generation and role of eddy variability in the central North Atlantic Ocean. J. Geophys. Res., 99, 20 381-20 391.

Böning, C., and R. G. Budich, 1992: Eddy dynamics in a primitive equation model: Sensitivity to horizontal resolution and friction. J. Phys. Oceanogr., 22, 361-381.

Bryan, F., and W. R. Holland, 1989: A high resolution simulation of the wind- and thermohaline-driven circulation in the North Atlantic Ocean. Proc. 'Aha Huliko'a Hawaiian WinterWorkshop, University of Hawaii, 99-115.

Bryden, H. L., 1979: Poleward heat flux and conversion of available potential energy in Drake Passage. J. Mar. Res., 37, 1-22.

Charney, J., 1971: Geostrophic turbulence. J. Atmos. Sci., 28, 10871095.

Chelton, D. B., M. G. Schlax, D. L. Witter, and J. G. Richman, 1990: Geosat altimeter observations of the surface circulation of the Southern Ocean. J. Geophys. Res., 95, 17 877-17 903.

Cox, M. D., 1984: A primitive equation, three-dimensional model of the ocean. GFDL Ocean Group Tech. Rep. 1, Geophysical Fluid Dynamics Laboratory, Princeton University, Princeton, NJ.

De Szoeke, R. A., and M. D. Levine, 1981: The advective flux of heat by mean geostrophic motions in the Southern Ocean. DeepSea Res., 28, 1057-1085.

The FRAM Group, 1991: Initial results from a fine resolution model of the Southern Ocean. Eos, Trans. Amer. Geophys. Union, 72, 174-175.

Harrison, D. E., and A. R. Robinson, 1978: Energy analysis of open regions of turbulent flows-mean eddy energetics of a numerical ocean circulation experiment. Dyn. Atmos. Oceans., 2, 185-211.

Hellerman, S., and M. Rosenstein, 1983: Normal monthly wind stress over the World Ocean with error estimates. J. Phys. Oceanogr., 13, 1093-1104.

Hoffmann, H. E., 1985: The large-scale horizontal structure of the Antarctic Circumpolar Current from FGGE drifters. J. Geophys. Res., 90, 7087-7097.

Holland, W. R., 1975: Energetics of baroclinic oceans. Numerical Models of Ocean Circulation, National Academy Press, 168177.

Ivchenko, V. O., K. J. Richards, and D. P. Stevens, 1996: The dy- 
namics of the Antarctic Circumpolar Current. J. Phys. Oceanogr., 26, 753-774.

Johnson, G. C., and H. L. Bryden, 1989: On the size of the Antarctic Circumpolar Current. Deep-Sea Res., 36, 39-53.

Killworth, P. K., and M. M. Nanneh, 1994: On the isopycnal momentum budget of the Antarctic Circumpolar Current in the Fine Resolution Antarctic Model. J. Phys. Oceanogr., 24, 1201-1223.

Le Traon, P. Y., J. Stum, J. Dorandeu, and P. Gaspar, 1994: Global statistical analysis of Topex and Poseidon data. J. Geophys. Res., 99 (C12), 24 619-24 631.

Levitus, S., 1982: Climatological Atlas of the World Ocean. NOAA Prof. Paper 13 U.S. Govt. Printing Office, 173 pp.

Lorenz, E. N., 1955: Available potential energy and the maintenance of the general circulation. Tellus, 7, 157-167.

Marshall, J. C., 1981: On the parameterization of geostrophic eddies in the ocean. J. Phys. Oceanogr., 11, 257-271.

—, D. Olbers, H. Ross, and D. Wolf-Gladrow, 1993: Potential vorticity constraints on the dynamics and hydrography of the Southern Ocean. J. Phys. Oceanogr., 23, 465-487.

McWilliams, J. C., W. R. Holland, and J. S. Chow, 1978: A description of numerical Antarctic Circumpolar Currents. Dyn. Atmos. Oceans., 2, 213-291.

Oort, A. H., S. C. Ascher, S. Levitus, and J. P. Peixoto, 1989: New estimates of the available potential energy in the World Ocean. J. Geophys. Res., 94, 3187-3200.

_ L. L. A. Anderson, and J. P. Peixoto, 1994: Estimates of the energy cycle of the oceans. J. Geophys. Res., 99, 7665-7688.

Patterson, S. L., 1985: Surface circulation and kinetic energy distributions in the Southern Hemisphere oceans from FGGE drifting buoys. J. Phys. Oceanogr., 15, 865-884.

Rhines, P. B., 1977: The dynamics of unsteady currents. Marine Mod- elling, Vol. 6, The Sea, E. D. Goldberg, I. N. McCane, J. J. O'Brien, and J. H. Steele, Eds., John Wiley, 189-318.

Stevens, D. P., 1990: On open boundary conditions for three dimensional primitive equation ocean circulation models. Geophys. Astrophys. Fluid Dyn, 51(1-4), 103-133.

- and P. D. Killworth, 1992: The distribution of kinetic energy in the Southern Ocean: A comparison between observations and an eddy resolving general circulation model. Philos. Trans. Roy. Soc. London B, 338, 251-257.

- , and V. O. Ivchenko, 1996: The zonal momentum balance in a realistic eddy resolving general circulation model of the Southern Ocean. Quart. J. Roy. Meteor. Soc., in press.

Thompson, S. R., 1993: Estimation of the transport of heat in the Southern Ocean using a fine-resolution numerical model. J. Phys. Oceanogr., 23, 2493-2497.

Toggweiler, J. R., and B. Samuels, 1995: Effect of Drake passage on the global thermohaline circulation. Deep-Sea Res., 42, 477500 .

Treguier, A. M., 1992: Kinetic energy analysis of an eddy resolving, primitive equation model of the North Atlantic. J. Geophys. Res. 97, 687-701.

, and J. C. McWilliams, 1990: Topographic influences on winddriven, stratified flow in a $\beta$-plane channel: An idealized model for the Antarctic Circumpolar Current. J. Phys. Oceanogr., 20, 321-343.

Webb, D. J., P. D. Killworth, A. C. Coward, and S. R. Thompson, 1991: The FRAM Atlas of the Southern Ocean. Natural Environment Research Council, Swindon, U.K., 67 pp.

Wolff, J.-O., E. Maier-Reimer, and D. J. Olbers, 1991: Wind-driven flow over topography in a zonal $\beta$-plane channel: A quasigeostrophic model of the Antarctic Circumpolar Current. J. Phys. Oceanogr., 21, 236-264. 